\title{
Spatial clustering for district heating integration in urban energy systems: application to geothermal energy ${ }^{\text {负 }}$
}

\author{
Jérémy Unternährer ${ }^{\mathrm{a}, 1, *}$, Stefano Moret ${ }^{\mathrm{a}}$, Stéphane Joost ${ }^{\mathrm{b}}$, François Maréchal $^{\mathrm{a}}$ \\ ${ }^{a}$ Industrial Process and Energy Systems Engineering Laboratory, École Polytechnique Fédérale de Lausanne (EPFL), Rue de l'Industrie 17, P.O. Box 440, \\ CH-1951 Sion, Switzerland \\ ${ }^{b}$ Laboratory of Geographic Information Systems (LASIG), School of Architecture, Civil and Environmental Engineering (ENAC), École Polytechnique Fédérale de \\ Lausanne (EPFL), CH-1015 Lausanne, Switzerland
}

\begin{abstract}
Given the challenges related to climate change and dependency from fossil fuels, modification of the energy systems infrastructure to increase the share of renewable energy is a priority in urban energy planning. The high heating density in cities makes it more economically competitive to deploy district heating (DH), which is essential for large-scale integration of renewable energy sources. Combining georeferenced data with district heating design methods allows to improve the quality of the system design. However, increasing the spatial resolution can lead to intractable model sizes.

This paper presents a methodology to spatially assess the integration of DH networks in urban energy systems. Given georeferenced data of buildings, resource availability and road networks, the methodology allows the identification of promising sites for DH deployment. First, an Integer Linear Programming (ILP) model divides the urban system into spatial clusters (of buildings). Graph theory and routing methods are then used to optimally design the DH configuration in each cluster considering the road network in the routing algorithm. A Mixed-Integer Linear Programming (MILP) model is formulated in order to economically evaluate the DH integration over the whole urban area.

The proposed methodology is applied to an example case study, evaluating the use of geothermal energy (deep aquifer) for direct heat supply. The results of the optimization show the interest of deploying geothermal DH in some of the clusters. The profitability of DH integration is strongly affected by the spatial density of the heating demand.
\end{abstract}

Keywords: Spatial Clustering, Urban energy systems, District Heating Network, Optimization, Geographic Information Systems (GIS), Routing

\section{Introduction}

In Western Europe and North America, space heating (SH) ${ }^{19}$ and domestic hot water (DHW) are the main contributors to ${ }^{20}$ household energy demand. In European residential buildings, ${ }_{21}$ about $57 \%$ of the total final energy consumption is used for $\mathrm{SH}_{22}$ and $25 \%$ for DHW [5]. The European heat market for buildings ${ }_{23}$ is dominated by fossil fuels burned in decentralized boilers, ac- ${ }_{24}$ counting for two-thirds of the total domestic heat supply [6]. $\operatorname{In}_{25}$ the residential buildings of the United States (US), $93.5 \%$ of 26 the energy used for space heating is provided by natural gas, ${ }_{27}$ fuel oil, liquefied petroleum gas, and kerosene [2]. Concerns 28 related to greenhouse gas emissions, climate change and secu- ${ }_{29}$ rity of energy supply are gradually leading to modifications in ${ }_{30}$ the thermal energy supply chain. Local authorities are pushed ${ }_{31}$ to make strategic decisions for the planning of heat supply, en- ${ }_{32}$ couraging the energy transition towards a low carbon future. $\operatorname{In}_{33}$

\footnotetext{
Electronic Supplementary Information (ESI) available.

${ }^{*}$ Corresponding author

Email address: jeremy. unternaehrer@gmail. com (Jérémy Unternährer)

${ }^{1}$ Present address: Chemin du Brunchenal 29b, 2805 Soyhières, Switzerland. 39
}

this framework, substitution of fossil fuels with renewable energy resources has been identified as a priority [14]. Thus, the optimal use of renewable energy resources and the sustainability of energy systems represent key issues in energy planning.

In 2010, approximately $73 \%$ of European Union (EU) residents lived in urban areas [6], where the highest share of the $\mathrm{SH}$ and DHW demand is concentrated. The high density of heat demand in cities makes the deployment of DH more competitive [15] as it leads to lower DH network lengths, lower thermal heat losses and therefore lower investment costs. Furthermore, DH offers the possibility of integrating heat resources that could otherwise not be used. These include excess heat from industrial processes, power plants or waste incineration. DH also allows to access large scale renewable energy resources such as geothermal, biomass or solar heat. DH penetration for heating of buildings in the EU was $13 \%$ in 2010 [6]. Nevertheless, the availability of resources reveals an important potential for DH expansion in some European countries [3]. As an example, in North-Eastern Europe more than 100 million people already depend on DH [26]. In Denmark, DH is the dominant heat carrier, accounting for $60 \%$ of total heat supply in 2009 [30]. As a comparison, in Switzerland DH provided only $2.8 \%$ of the heat demand in 2007 [28]. Many studies analyze the potential of DH 
related to specific case studies. For instance, Gebremedhin [23] 97 studied the impact of DH in the city of Gjonik in Norway and 98 concluded that $\mathrm{DH}$ can lead to a significant reduction in terms 99 of $\mathrm{CO}_{2}$ emissions.

Among renewable energy sources for $\mathrm{DH}$, some studies have $\mathrm{e}_{101}$ highlighted the interest of geothermal energy integration. Hep-102 basli et al. [24] and Moret et al. [25] assessed that geothermal ${ }_{103}$ DH can provide heat at a lower cost than fossil fuel alternatives 104 in the cities of Izmir, Turkey, and Lausanne, Switzerland,105 respectively. Globally, geothermal energy accounted for $0.1 \% 106$ of the energy supply in 2008 [14]. It is projected to cover 3.5107 $\%$ of the global electricity production and $3.9 \%$ of the final 108 energy for heat by 2050 [1]. Fox et al. [4] showed that there ${ }_{109}$ is a large potential for utilizing low-temperature geothermal ${ }_{110}$ resources to meet the heating demand by direct heat use.111 Aquifers located under cities can naturally offer interesting ${ }_{112}$ thermal conditions for building heat supply. As an example, the $e_{13}$ DH of Riehen, Switzerland, is mainly supplied by an aquifer, 114 from which around $25 \mathrm{~kg} / \mathrm{s}$ of water at $65^{\circ} \mathrm{C}$ are extracted [29].115

Optimization models taking into account energy demand, roy resources and energy conversion technologies are often de-18 veloped to support the understanding and planning of urban en-119 ergy systems. Due to the spatial dimension of the problem, the $e_{120}$ use of georeferenced data is essential for assessing and prelim-12 inary designing $\mathrm{DH}$ solutions. In fact, the spatial configuration ${ }_{122}$ of the buildings connected to the DH network defines its length ${ }_{123}$ and, consequently, its investment cost. In large cities such as 124 London [35] and Berlin [36], Geographic Information Systems 125 (GIS) are used to analyze and visualize the heat demand distri-126 bution in the city. Finney et al. [7] used GIS in order to inves-127 tigate the expansion possibilities of DH systems by identifying ${ }_{128}$ the existing and emerging heat sources and sinks. The method-129 ology is solely based on heat mapping, i.e. the heat sources as 130 well as the heat sinks in Sheffield, England, are identified and $d_{131}$ mapped. Nielsen et al. [8] developed a GIS model to examine ${ }_{132}$ the potential for expanding DH in Denmark. This is performed ${ }_{133}$ by determining the cost of deploying $\mathrm{DH}$ in urban areas that ${ }_{134}$ are not yet served. The output of the GIS-model consists of $a_{135}$ map showing the economic potential of each area for DH in-136 tegration compared with individual ground source heat pumps,137 which are assumed to be the cheapest decentralized heat supply ys $_{13}$ alternative. In their study, the areas in which DH expansions 139 are evaluated are taken from the Danish Common Public Geo-140 database [34]. Möller et al. [9] presented a geographical study ${ }_{141}$ of the potential to expand $\mathrm{DH}$ into areas supplied with natu-142 ral gas. Their study uses a highly detailed spatial database of ${ }_{143}$ the built environment, its current and potential future energy 144 $_{14}$ demand, its supply technologies and its location relative to en-145 ergy infrastructure. The cost of district heat expansion is eval-146 uated as a function of the heat demand density in the areas, the ${ }_{147}$ number of buildings to be connected, as well as the straight ${ }_{148}$ line distance to the existing network. Cost-supply curves based ${ }_{149}$ on empirical methods are used to assess economic potential for ${ }_{150}$ district heat expansion. Girardin et al. [11] developed a GIS-151 based approach in order to evaluate the best zones to be covered ${ }_{152}$ by a DH system in a given geographical area. The geographical ${ }_{153}$ area is first divided into subsectors using the statistical sectors provided by the authorities. An algorithm is proposed to estimate the DH network length connecting a set of buildings. The length is computed based on the number of buildings, the area covered by the buildings and a topological factor. Based on the equidistance assumption, the model considers the calculated peak heat load to estimate the section of the pipes and the required investment. In his thesis, Girardin [12] extended the approach using a GIS-based Mixed-Integer Linear Programming (MILP) aggregation mechanism in order to evaluate the best zones to be covered by a DH system that has access to a limited but high quality resource such as a waste water treatment plant. As shown in [11], the evaluation of the length and the costs of future networks is an important issue in territorial energy planning. Reidhav et al. [16] evaluated the investment cost of new DH networks based on data relating to an existing DH network in Göteborg. The investment cost is empirically defined as a linear function of the district heat delivered per connected house. Persson et al. [15] proposed a method to estimate the distribution cost of a future DH system based on the concept of linear heat density, which corresponds to the ratio between the heat annually sold and the total trench length. The linear heat density is reformulated and estimated based on a set of parameters (such as the effective width initially introduced in 1997 in [13]) that are empirically defined. Falke et al. [17] developed a method to determine the optimal heating network design based on a heuristic approach that randomly generates a variety of different DH network configurations for a specific district.

In case of highly populated cities, the current computational capacities do not allow the inclusion of each building as a single instance in optimization models. Fazlollahi [32] underlined that the size of an optimization model for urban energy design can increase considerably with the number of buildings. Thus, optimization-based energy models are often limited to a small number of buildings or a limited list of options (i.e. number of conversion technologies, buildings and network). In order to reduce the number of decision variables and thus the computational complexity, buildings can be aggregated into a smaller number of clusters making up the city. A cluster is defined as a spatially-limited energy subsystem including an aggregated energy demand (sum of the energy demand of the buildings in the cluster) and a set of available technologies for energy supply.

Data clustering is widely applied in several disciplines to decrease computational time and reliability of results. Lam et al. [10] proposed several model-size reduction techniques for the analysis of large-scale biomass production and supply networks. The proposed merging method offers the best results but it is not described as an automatic process. The zones are manually structured based on the geographical locations, the capacities of the zones and the regional development planning. Fazlollahi et al. [32] presented a systematic procedure to represent an urban energy system with a macroscopic view as a set of clusters. Clusters are formed by applying $k$-means clustering techniques [33]. The method achieves a representation of the whole district while significantly reducing the number of decision variables of the optimization model. No optimization is 
performed for the clustering and the clusters can only be formed204 based on similarities between building attributes.

Thus, the main gaps identified in the literature are the fol-206 lowing: i) Some studies do not include optimization methods207 such as MILP for optimally designing urban energy systems.208 Instead, only comparative analyses among different scenarios 209 using simulation models are performed. ii) Even when lin-210 ear programming is included ([11] and [32]), the approaches 211 are not adapted for the integration of a non-spatially limited ${ }^{2}$ resource. Urban zoning based on the k-means method or on 213 statistical sectors do not offer the possibility to fully control 214 the cluster-formation process. As an example, constraints forc-215 ing the cluster sizes to meet the potential of a given resource 216 (e.g. geothermal well) can not be imposed. iii) Furthermore,217 no method in the literature considers road networks for realisti-218 cally connecting together all the buildings included in a future 219 DH system.

Consequently, this paper presents an optimization-based 221 methodology to spatially assess the integration of DH networks222 in urban energy systems. The two novel contributions of our 223 work are: $i$ ) first an Integer Linear Programming (ILP) ap-224 proach is proposed for the spatial clustering of urban energy 225 system models. In practical applications, this is often an es-226 sential step to reduce model complexity. The ILP approach 227 combined with georeferenced data allows to fully control the 228 cluster formation process. In this way, the heating demand of 229 each cluster of buildings can meet the potential of the energy 2зо resource of interest. ii) Second, routing techniques are used ${ }_{231}$ to define realistic spatial configurations of DH network. The 232 pipelines path is optimized in order to reduce the related costs233 and the thermal losses. The routing forces the $\mathrm{DH}$ pipelines to follow the road network. The quality of the method is assessed $d_{234}$ by comparing the obtained network configurations with existing DH networks

The developed methodology is illustrated with an applied ${ }_{236}$ case study. The integration of geothermal energy in the $\mathrm{City}_{237}$ of Lausanne (Switzerland, 140'421 inhabitants) is taken as an example case study in this work. An aquifer located under the city represents a promising heat resource.

First the methodology is presented including the data collec- ${ }^{240}$ tion, the spatial clustering, the estimation of the network lengths and the general formulation of the MILP urban energy model ${ }^{24}$ (Section 2). Then, the results are obtained with the systematic application of the methodology to the specified case study (Sec- ${ }^{242}$ tion 3 .

\section{Methodology}

Figure 1 offers an overview of the methodology. It is struc-247 tured in four phases: 1) data collection, 2) spatial clustering, 32248 estimation of DH network length and 4) cluster-oriented model-249 ing. After collecting building related data, the energy resources250

${ }^{2} \mathrm{~A}$ non-spatially limited resource is defined as a resource which can be ex- 252 ploited everywhere in an area (e g. geothermal energy resource). On the other ${ }^{-} 23$ hand, a spatially limited resource has a specific location (e.g. waste heat from ${ }^{254}$ a power plant). and the road network, spatial clustering methods are applied on the buildings of the city that are not already connected to a DH network. This step is itself divided into two sub-steps: a preliminary clustering (optional) and the main clustering. The main clustering is defined as an ILP problem. It aims at grouping the buildings into different clusters. The objective function is the minimization of the total distance between the buildings belonging to the same clusters. Buildings heating demand data and availability of the resource are used in order to define the constraints of the problem. A preliminary clustering based on the $k$-means method [33] is needed only when the calculation load of the main clustering algorithm is too heavy. The objective of this step is to form small building groups (called subclusters), which are then used as inputs for the main clustering step. Georeferenced buildings are not required in the main clustering step if the preliminary clustering is performed.

Based on the cluster configurations and on the road network of the city, the minimum path connecting all the buildings in a cluster is estimated. This step results from the combination of different algorithms. The buildings are considered as components of a graph as vertices. Delaunay triangulation [19] is applied to define the edge configuration of the graphs. Based on the road network (routing) and on the Johnson's algorithm [21], the minimum path length connecting two buildings is computed and corresponds to the weight of the edge that links these buildings. Then, the Kruskal's algorithm [20] defines the minimum spanning tree connecting all the buildings together.

Finally, a MILP urban energy system model based on the clusters configuration and on the DH network lengths is applied to economically evaluate DH integration in each cluster.

\subsection{Data collection}

Four datasets are necessary:

1. The geographic coordinates of the buildings (longitude $X$ and latitude Y).

2. The SH demand and the DHW demand of the buildings.

3. The spatial distribution of the energy resource.

4. The georeferenced road network of the city.

These data can often be provided by the local authorities.

\subsection{Spatial clustering}

\subsubsection{Preliminary clustering}

Running out of memory is a very common difficulty with ILP problems. This occurs when the branch\&cut tree reaches sizes bigger than the available memory. Solving the main clustering is not possible if the number of buildings is too large. Thus, a preliminary clustering is performed using the $k$-means clustering algorithm [33] and georeferenced data. It is an efficient, fast and simple method to group data points according to their characteristics. This method is applied to divide a set of $\mathrm{N}_{\mathrm{b}}$ buildings into $\mathrm{N}_{\mathrm{s}}$ subclusters according to their $\mathrm{X}$ and $\mathrm{Y}$ coordinates. The number of subclusters $\mathrm{N}_{\mathrm{s}}$ is a required input to the algorithm. The method aims by iterative resolution at finding the position of the subclusters' centers $\mu_{s} \in\left[\mu_{1}, \ldots, \mu_{\mathrm{N}_{\mathrm{s}}}\right]$ which 

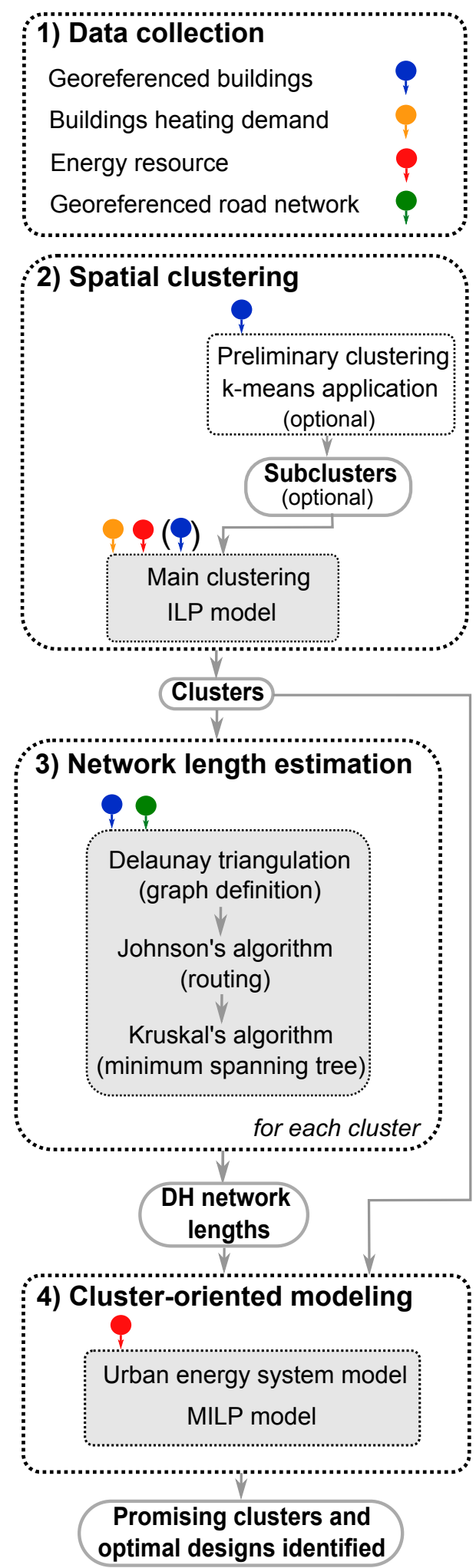

Figure 1: Overview of the entire methodology. Data types are represented with colored symbols in order to show in which steps they are involved and used as inputs. minimizes the total distance from the buildings to their respective subcluster's centroids. Thus, the objective function of the applied k-means process is expressed as follows:

$$
\min \sum_{\mathrm{s}=1}^{\mathrm{N}_{\mathrm{s}}} \sum_{\mathrm{b} \in \mathrm{B}_{\mathrm{s}}}\left[\left(\mathrm{X}_{\mu_{\mathrm{s}}^{\gamma}}-\mathrm{X}_{\mathrm{b}}\right)^{2}+\left(\mathrm{Y}_{\mu_{\mathrm{s}}^{\gamma}}-\mathrm{Y}_{\mathrm{b}}\right)^{2}\right] \quad \forall \gamma
$$

where $b \in\left[1, \ldots, N_{b}\right]$ represents the building's index. $B_{s}$ is the set of buildings which are assigned to the subcluster $\mathrm{s}$. The results of the k-means method depend on the starting cluster centroid positions ("seed" randomly set). Thus, the clustering is repeated several times using new initial cluster centroid positions and the configuration leading to the best value of objective function is selected. $\gamma \in\left[1, \ldots, \gamma_{\max }\right]$ is an index corresponding to the starting cluster centroids where $\gamma_{\max }$ is the last starting points configuration which will be tested. The algorithm uses an iterative technique which is explained in details in the Electronic Supplementary Information (ESI). The preliminary clustering leads to $\mathrm{N}_{\mathrm{s}}$ spatially compact subclusters. On the one hand, a high number of subclusters improves the accuracy of the ILP model. On the other hand, the available computational resources limit the ILP problem size. Thus, there is a trade-off in defining the optimal number of initial subclusters. $\mathrm{N}_{\mathrm{s}}$ is maximized as available computational resources permit (see section 3.3 .

\subsubsection{Integer Linear Programming model}

This section presents the ILP model which aims at aggregating subcluster ${ }^{3}$, with the objective of minimizing the total cost of connection. It is expressed as follows:

$$
\begin{aligned}
& \min \sum_{i=1}^{\mathrm{N}_{\mathrm{s}}} \sum_{j=1}^{\mathrm{N}_{\mathrm{s}}} \mathrm{d}_{i, j} y_{i, j} \\
& \text { s.t. } \sum_{i=1}^{\mathrm{N}_{\mathrm{s}}} y_{i, j}=1 \\
& \sum_{j=1}^{\mathrm{N}_{\mathrm{s}}} \mathrm{p}_{j} y_{i, j} \leq v_{\max } y_{i, i} \\
& \sum_{j=1}^{\mathrm{N}_{\mathrm{s}}} \mathrm{p}_{j} y_{i, j} \geq v_{\min } y_{i, i} \\
& \sum_{i=1}^{\mathrm{N}_{\mathrm{s}}} y_{i, i} \leq \frac{\sum_{j=1}^{\mathrm{N}_{\mathrm{s}}} \mathrm{p}_{j}}{v_{\min }} \\
& \sum_{i=1}^{\mathrm{N}_{\mathrm{s}}} y_{i, i} \geq \frac{\sum_{j=1}^{\mathrm{N}_{\mathrm{s}}} \mathrm{p}_{j}}{v_{\max }}
\end{aligned}
$$

The configuration of the clusters is defined by the binary decision variables $y$. They are represented in a $\mathrm{N}_{\mathrm{s}} \mathrm{xN}_{\mathrm{s}}$ matrix $Y$, defined as follows:

\footnotetext{
3"Subcluster" can be replaced by "building" in this section if the preliminary clustering step is skipped
} 


$$
Y=\left(\begin{array}{ccc}
y_{1,1} & \ldots & y_{1, \mathrm{~N}_{\mathrm{s}}} \\
\cdots & \ldots & \ldots \\
y_{\mathrm{N}_{\mathrm{s}}, 1} & \ldots & y_{\mathrm{N}_{\mathrm{s}}, \mathrm{N}_{\mathrm{s}}}
\end{array}\right)
$$

where $\mathrm{N}_{\mathrm{s}}$ is the number of subclusters. $y_{i, j}$ is a binary decision variable that declares if the subcluster $j$ belongs or not to the cluster $i$ : if $y_{i, j}=1$ the subcluster $j$ belongs to the cluster $i$, if $y_{i, j}=0$ the subcluster $j$ does not belong to the cluster $i$. Each row $Y$ corresponds to a potential cluster $i$ and each column represents the subclusters which can be included or not in each cluster. If a row contains only zeros, then no cluster is defined on that row. If a row has at least one non-zero element, it means that a cluster is defined on this row. The other non-zero elements on the row show the other subclusters which are part of the cluster, identified by their relative column number. The row number identifies the central subcluster in each cluster.

The objective of the problem is the minimization of the sum of all intra-distances of all clusters (Eq. 2). By definition, the intra-distance of a cluster formed on row $i$ is defined as the sum $_{327}$ of the Euclidean distances between the subclusters included in this cluster and the subcluster $i$. The Euclidean distance is chosen if the preliminary clustering is applied (see section 2.2.1) as a subcluster can not be linked to a specific road. If the preliminary clustering step is skipped and buildings are used as input of the ILP model, Euclidian distances can be replaced by road distances, computed as in section 2.3.2. The intra-distance of the cluster corresponding to row $i$ is defined as follows:

$$
\sum_{j=1}^{\mathrm{N}_{\mathrm{s}}} \mathrm{d}_{i, j} y_{i, j}
$$

The subcluster $i$ is the center of the cluster corresponding to ${ }^{333}$ the row $i$. The Euclidean distances between the subclusters are ${ }^{334}$ represented in a symmetric matrix $D$ as follows:

$$
\mathrm{D}=\left(\begin{array}{ccc}
\mathrm{d}_{1,1} & \ldots & \mathrm{d}_{1, \mathrm{~N}_{\mathrm{s}}} \\
\ldots & \ldots & \ldots \\
\mathrm{d}_{\mathrm{N}_{\mathrm{s}}, 1} & \ldots & \mathrm{d}_{\mathrm{N}_{\mathrm{s}}, \mathrm{N}_{\mathrm{s}}}
\end{array}\right)
$$

$\mathrm{d}_{\mathrm{i}, \mathrm{j}}$ is the Euclidean distance between the subcluster $i$ and the ${ }^{336}$ subcluster $j$ and it is defined as follows:

$$
\mathrm{d}_{i, j}=\sqrt{\left(\mathrm{X}_{\mu_{i}}-\mathrm{X}_{\mu_{j}}\right)^{2}+\left(\mathrm{Y}_{\mu_{i}}-\mathrm{Y}_{\mu_{j}}\right)^{2}}
$$

$\mathrm{X}_{\mu}$ and $\mathrm{Y}_{\mu}$ are the longitudinal and latitudinal coordinate ${ }_{340}$ of the subcluster centroids, respectively. The diagonal of the ${ }_{34}$ matrix $D$ contains only zeros since $d_{i, i}=0$. Figure 2 illustrates ${ }_{343}$ these distances separating the subclusters with a 2-dimensional ${ }_{344}$ example.

Eq. 3 forces each subcluster to be included in only one cluster.

The heating power demand of clusters is the sum of the heating power demands of the subclusters included in it. The pa- ${ }^{346}$ rameter $\mathrm{P}$ contains the heating power demands of the subclus- ${ }^{347}$ ters. The heating power demands considered in this ILP process ${ }^{348}$ depend on the conditions and the objectives of the applied case ${ }^{349}$ study. As an example, in the case study presented later in this 350 work (see section 3.3), the heating power demands are defined $\mathrm{d}_{351}$

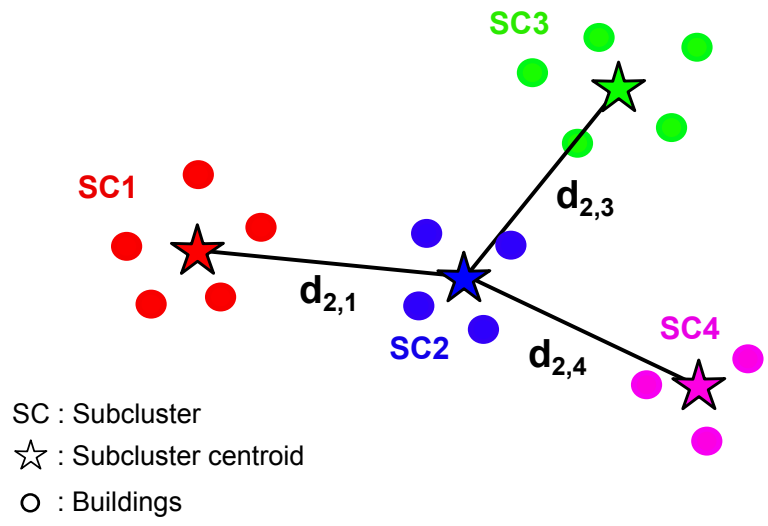

Figure 2: Illustration of the Euclidean distances between different subclusters In this example, a cluster includes the subclusters SC1, SC2, SC3 and SC4. $\mathrm{SC} 2$ is the center of the cluster from which the distances are computed.

by the base load demand of the buildings which corresponds to the DHW.

$$
P=\left(\begin{array}{c}
\mathrm{p}_{1} \\
\cdots \\
\mathrm{p}_{\mathrm{N}_{\mathrm{s}}}
\end{array}\right)
$$

The heating power demand of the resulting clusters must be in the range defined by a lower bound $v_{\min }$ and an upper bound $v_{\max }$ (Eq. 4 and Eq. 5). $v_{\max }$ corresponds to the heating power available from the energy resource. Since the clusters have to be adapted to the energy resource, the clusters' heating demand should be close to $v_{\max }$. Thus, a lower limit $v_{\min }$ is arbitrarily defined. In this work, it is chosen as the difference between $v_{\max }$ and the third quartile of $\mathrm{P}$.

$$
v_{\min }=v_{\max }-Q_{3}(\mathrm{P})
$$

This difference between $v_{\min }$ and $v_{\max }$ offers flexibility to the solver in defining the cluster configuration.

Additional constraints are added in order to reduce the solution domain and save computational time (Eq. 6 and Eq. 7). The number of resulting clusters can be preliminary estimated as its limits depend directly on the total heating demand of the buildings and on the fixed bounds $v_{\min }$ and $v_{\max }$. Thus, the maximum (minimum) number of clusters is equal to the sum of all heating powers included in $P$ divided by the lower (upper) bound $v_{\min }\left(v_{\max }\right)$

Example application. For a better understanding, an example is provided. Figure 3 illustrates a simplified configuration with 8 subclusters aggregated into 2 clusters. The abbreviation SC is used for 'subcluster'.

The corresponding matrix $Y$ calculated by the solver in this example is shown in Eq. 14 


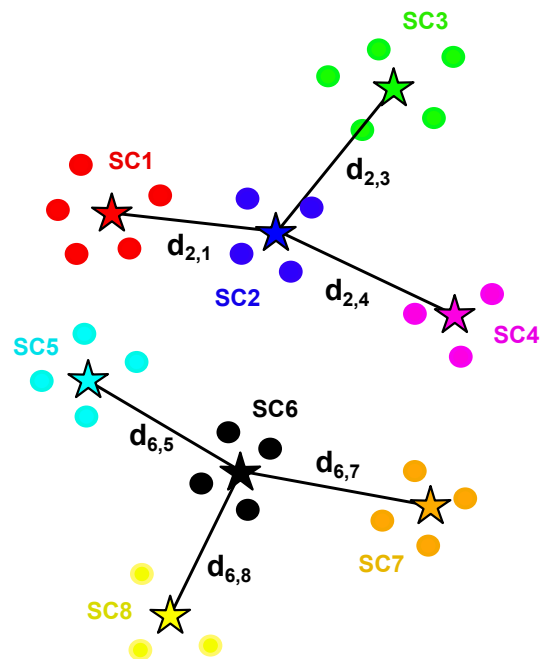

Figure 3: Example application of the ILP algorithm. The subclusters (SC)388 are aggregated into two clusters. A cluster includes the subclusters SC1, SC2, SC3 and SC4, while another cluster includes the subclusters SC5, SC6, SC7 and SC8. The centers of the clusters corresponds to SC2 and SC6. The intra- ${ }^{390}$ distance of the first cluster is composed of $\mathrm{d}_{2,1}, \mathrm{~d}_{2,3}$ and $\mathrm{d}_{2,4}$. The intra-distance391 of the second cluster is composed of $\mathrm{d}_{6,5}, \mathrm{~d}_{6,7}$ and $\mathrm{d}_{6,8}$.

$$
Y_{\text {example }}=\left(\begin{array}{llllllll}
0 & 0 & 0 & 0 & 0 & 0 & 0 & 0 \\
1 & 1 & 1 & 1 & 0 & 0 & 0 & 0 \\
0 & 0 & 0 & 0 & 0 & 0 & 0 & 0 \\
0 & 0 & 0 & 0 & 0 & 0 & 0 & 0 \\
0 & 0 & 0 & 0 & 0 & 0 & 0 & 0 \\
0 & 0 & 0 & 0 & 1 & 1 & 1 & 1 \\
0 & 0 & 0 & 0 & 0 & 0 & 0 & 0 \\
0 & 0 & 0 & 0 & 0 & 0 & 0 & 0
\end{array}\right)
$$

The matrix $Y$ in Eq. 14 shows that two clusters were created ${ }^{402}$ because two rows contained at least a 1 . The cluster which is defined on row 2 is called $c_{1}$ and the cluster which is defined on row 6 is called $c_{2}$. Since the clusters are defined in rows 2 and 6, the centers of the clusters $c_{1}$ and $c_{2}$ are SC2 and SC6, respectively. Thus, the intra-distances of the clusters $c_{1}$ and $c_{2}$ are based on SC2 and SC6 respectively. In addition, the matrix defines the composition of the clusters. As $y_{2,1}, y_{2,2}, y_{2,3}, y_{2,4}$ are equal to $1, \mathrm{c}_{1}$ is composed of $\mathrm{SC} 1, \mathrm{SC} 2, \mathrm{SC} 3$ and $\mathrm{SC} 4$. In the same way, $\mathrm{c}_{2}$ is composed of SC5, SC6, SC7 and SC8. The intra-distance of $c_{1}$ is the sum of $d_{2,1}, d_{2,3}$ and $d_{2,4}$. The intradistance of $c_{2}$ is the sum of $d_{6,5}, d_{6,7}$ and $d_{6,8} . d_{2,2}$ and $d_{6,6}$ are equal to zero. The objective value is the global sum of the intra-distances.

The expression of the ILP problem problem ensures that:

- The resulting cluster configuration leads to a minimum sum of the intra-distances. This is controlled by the $\mathrm{ob}_{-406}$ jective of the ILP model.

- The heating power demand of clusters $c_{1}$ and $c_{2}$ is in-409 cluded between $v_{\min }$ and $v_{\max }$. This is controlled by the 410 constraints.

\subsection{Estimation of the length of the DH networks}

The goal of this section is to estimate the length of the $\mathrm{DH}$ networks $\left(\mathrm{L}_{\mathrm{DH}}\right)$ in each cluster. The lengths are computed based on graph theory methods [22]. In this framework, the buildings are the vertices whereas the possible DH network paths are the edges. Each edge is assigned a weight. As the DH pipelines are generally constrained by the road network, the weight of each edge corresponds to the length of the shortest path connecting the buildings located along the road network. DH network length is calculated by applying one after the other the Delaunay triangulation [19], the Johnson's algorithm [21] and the Kruskal's algorithm [20]. It is assumed that the DH network modeled in a given cluster connects all the buildings belonging to this cluster. Thus, for each cluster, the algorithms are applied to the entire set of buildings.

\subsubsection{Delaunay triangulation: graph definition}

The Delaunay triangulation [19] is used to define a configuration of edges which connect all the buildings together in a cluster. The set of vertices and edges forms a planar graph. The use of a planar graph ensures that the possibility of connecting buildings that are far away from each other is excluded. Additionally, the Delaunay triangulation maximizes the minimum angle of the triangles in order to avoid skinny triangles. From a set $\mathrm{B}_{\mathrm{c}_{\mathrm{k}}}$ corresponding to the buildings included in the cluster $\mathrm{c}_{\mathrm{k}}$, the Delaunay triangulation defines an optimized planar and connected graph $\mathrm{G}_{\mathrm{c}_{\mathrm{k}}}$ in order to create paths between each pair of buildings. The triangulation is based on the building locations and on the Euclidean distances between them.

$$
\mathrm{G}_{\mathrm{c}_{\mathrm{k}}}=\left(\mathrm{B}_{\mathrm{c}_{\mathrm{k}}}, \mathrm{E}_{\mathrm{c}_{\mathrm{k}}}\right) \quad \forall \mathrm{k} \in\left[1, \ldots, \mathrm{N}_{\mathrm{c}}\right]
$$

$\mathrm{B}_{\mathrm{c}_{\mathrm{k}}}$ and $\mathrm{E}_{\mathrm{c}_{\mathrm{k}}}$ correspond to the set of vertices and to the set of edges of $\mathrm{G}_{\mathrm{c}_{\mathrm{k}}}$ respectively. $\mathrm{N}_{\mathrm{c}}$ is the total number of clusters. $\mathrm{e}_{i, j}$ is the edge connecting buildings $i$ and $j$. As an example, Figure 4 illustrates the application of the Delaunay triangulation to a set of buildings.

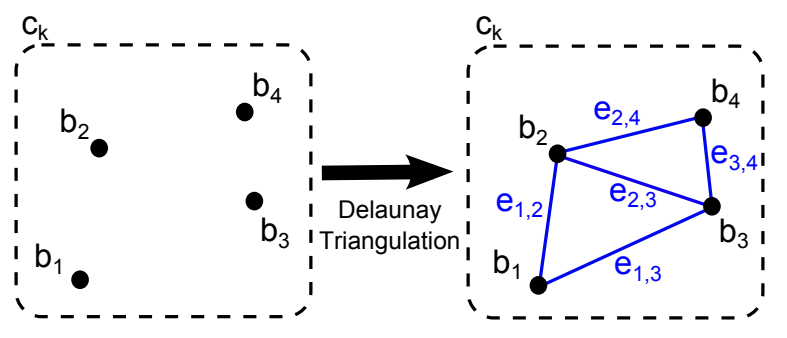

Figure 4: Example of a Delaunay triangulation applied to a small set of buildings $b_{i}$ included in a cluster $c_{k}$. $B_{c_{k}}$ corresponds to the vertices set $\left[b_{1}, b_{2}, b_{3}\right.$, $\left.b_{4}\right]$ and $E_{c_{k}}$ corresponds to the edges set $\left[e_{1,2}, e_{1,3}, e_{2,3}, e_{2,4}, e_{3,4}\right]$. As the graph is planar, there is no connection between $b_{1}$ and $b_{4}$.

\subsubsection{Johnson's algorithm: routing}

The weights of the edges presented in Eq. 15 are the Euclidean distances between the buildings. However, these distances do not reflect realistic paths for DH networks. Thus, a new weight is computed for each edge on the basis of the road network. Johnson's algorithm [21] is used to find the shortest 
paths between all pairs of buildings taking into account the road $_{437}$ network. Figure 5 shows an example of routing applied to two 438 buildings. The network is composed of road segments $r . l_{r}$ is 439 the length of the road segments $\mathrm{r}$. The new weight $\mathrm{d}_{i, j}$ is the $\mathrm{A}_{440}$ sum of $1_{r}$ for the road segments that compose the shortest path ${ }_{44}$ $\left(\mathrm{SP}_{i, j}\right)$ between the buildings $\mathrm{b}_{i}$ and $\mathrm{b}_{j}$ as expressed in Eq. 16.

$$
\mathrm{d}_{i, j}=\sum_{\mathrm{r} \in \mathrm{SP}_{i, j}} \mathrm{l}_{\mathrm{r}}
$$

If in the raw data the buildings are not directly linked to the road network, they are connected to their closest road segment before applying the Johnson's algorithm ${ }^{4}$. This forms additional road segments. As an example in Figure 5, $r_{1}$ and $r_{12}$ are additional road segments.

After defining the weights of the edges included in $\mathrm{E}_{\mathrm{c}_{\mathrm{k}}}$, the Kruskal's algorithm is applied in order to compute the shortest path to connect all the buildings in the cluster $c_{\mathrm{k}}$.

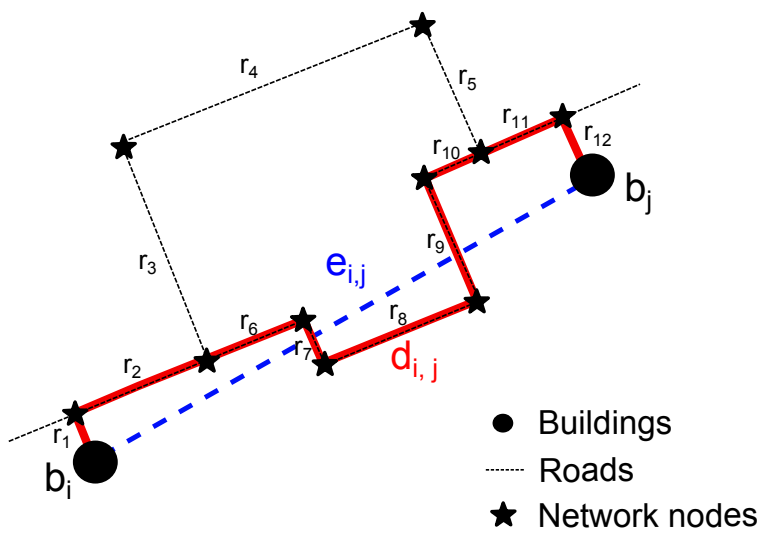

Figure 5: Application of the routing to two buildings. The edge weight $\mathrm{d}_{i, j}$ between the buildings $b_{i}$ and $b_{j} . d_{i, j}$ is the length of the minimum path connecting $\mathrm{b}_{i}$ and $\mathrm{b}_{j}$ following the road network. $\mathrm{e}_{i, j}$ is the edge generated by the Delaunay triangulation connecting $b_{i}$ and $b_{j}$. The segments $r$ are the road segments. The nodes of the road network are represented by star symbols and correspond to intersections or changes of direction.

\subsubsection{Kruskal's algorithm: minimum spanning tree}

The Kruskal's algorithm [20] determines the Minimum $_{447}$ Spanning Tree (MST) in a connected and undirected graph. $\mathrm{A}_{448}$ MST is a spanning tree (subset of vertices and edges without cycles connecting all vertices) in which the sum of the edges ${ }_{450}$ weights is minimal. In other words, this algorithm determines ${ }_{451}$ the shortest path connecting all the vertices according to the configuration of edges in a graph. The Kruskal's algorithm is applied to the graphs $\mathrm{G}_{\mathrm{c}_{\mathrm{k}}}$ presented in $\mathrm{Eq} 15$, using the edge weights computed with the Johnson's algorithm. Thus, a MST is defined in each cluster as follows:

$$
\operatorname{MST}_{\mathrm{c}_{\mathrm{k}}}=\left(\mathrm{B}_{\mathrm{c}_{\mathrm{k}}}, \mathrm{T}_{\mathrm{c}_{\mathrm{k}}}\right) \quad \forall \mathrm{k} \in\left[1 \ldots \mathrm{N}_{\mathrm{c}}\right]
$$

${ }^{4}$ These connections can be performed automatically by using the "Net- ${ }^{459}$ works" plug-in (https://github.com/crocovert/networks/) available for QGIS ${ }^{460}$ software 43
$\mathrm{T}_{\mathrm{c}_{\mathrm{k}}}$ is the set of edges of the MST included in the cluster $\mathrm{c}_{\mathrm{k}}$. The edges $t_{i, j}$ correspond to a subset of the edges $e_{i, j}$ which is chosen to form the MST. As an example, Figure 6 illustrates the Kruskal's algorithm application based on the previous example in Figure 4. The road network does not appear in Figure 4 for visualization reasons. However, the weights of the edges $e_{i, j}$ are based on the road distances as shown in Figure 5.

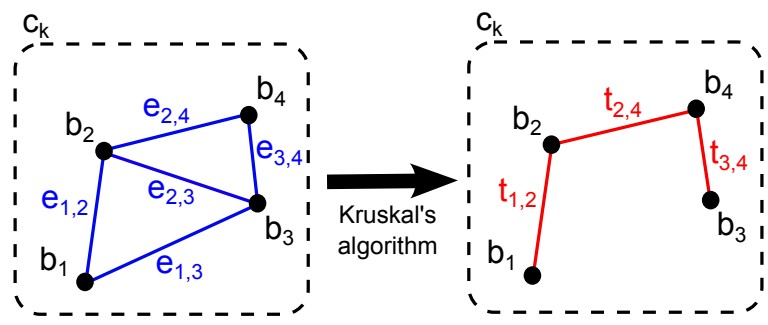

Figure 6: Kruskal's algorithm applied to a small set of buildings included in a cluster $c_{k}$. $T_{c_{k}}$ corresponds to the set of edges $\left[t_{1,2}, t_{2,4}, t_{3,4}\right]$.

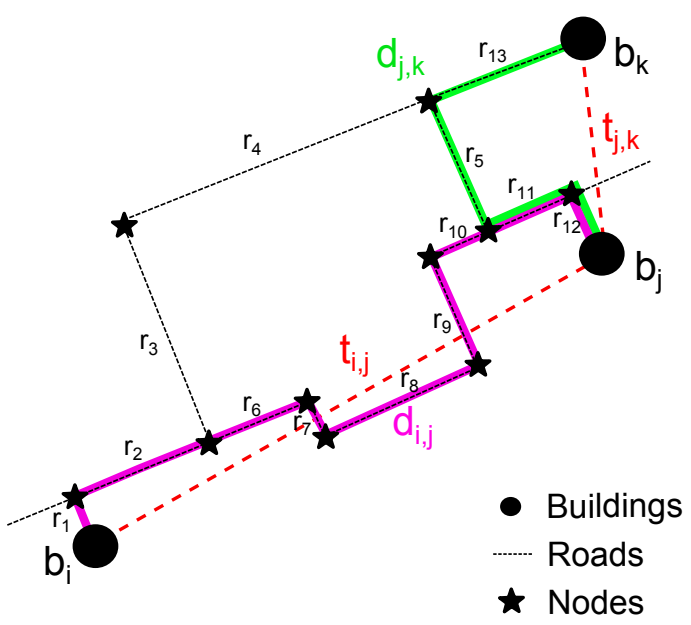

Figure 7: Minimum Spanning Tree connecting three buildings. Certain edges $r$ are taken into account in several weights $d$.

When calculating the length of the DH network, duplicates of road segments $r$ included in the weights of the MSTs need to be removed. As an example, in Figure 7 segments $r_{11}$ and $r_{12}$ are counted twice. The duplicates of $r_{11}$ and $r_{12}$ are removed. The length of the network linking the three buildings in Figure 7 is the sum of the lengths of the edges $r_{1}, r_{2}, r_{5}, r_{6}, r_{7}, r_{8}, r_{9}$, $\mathrm{r}_{10}, \mathrm{r}_{11}, \mathrm{r}_{12}$ and $\mathrm{r}_{13}$. More generally, the length of a DH network is defined as the sum of the edge lengths $l_{r}$ forming the shortest paths (SP) of the MST after removal of duplicates.

\subsection{Cluster-oriented energy system modeling}

Based on the obtained clusters configuration and the calculated DH lengths, a Mixed-Integer Linear Programming (MILP) urban energy system model is developed. It is a general formulation (superstructure) allowing all the possible configurations of investigated energy systems. The model is a simplified representation of an urban system accounting for the energy flows within its boundaries. The cluster-oriented model is represented in Figure 8 The same superstructure is defined for 
each of the clusters, but taking into account parameter values496 which are cluster-dependent (e.g. energy demand, DH length,497 etc...). In this way, the option of centralization can be evaluated ${ }_{498}$ simultaneously for all the clusters in the urban area.

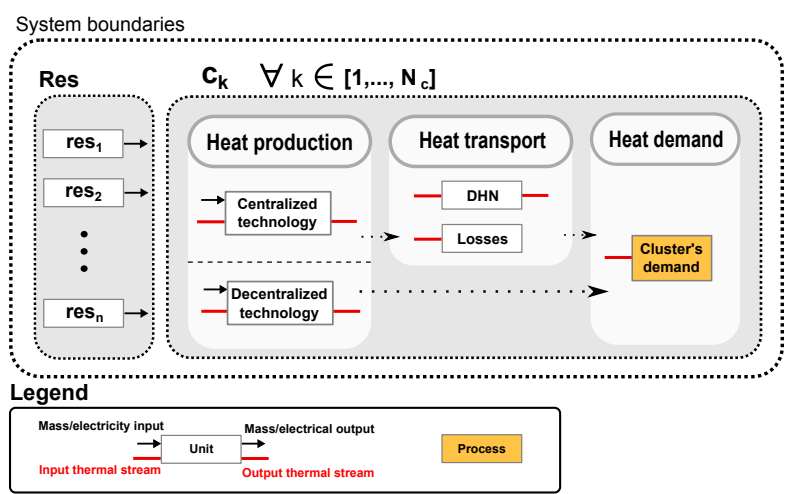

Figure 8: Conceptual cluster-oriented urban energy system model. Res is the abbreviation for resources.

The heating power demand of each cluster is the sum of the heating power demand ( $\mathrm{SH}$ and $\mathrm{DHW}$ ) of all the buildings included in the cluster. Resources are converted by energy conversion technologies in order to satisfy end-use energy demands such as SH and DHW. Heat production is separated into centralized and decentralized. For centralized cases, a DH network delivers the produced heat to the consumers. The heat delivered by decentralized technologies meets the heating demand directly. The DH option, if chosen, connects all the buildings in a cluster. Thus, the heating demand cannot be satisfied with a combination of centralized and decentralized technologies, i.e. the cluster heating demand is satisfied by either centralized technologies or decentralized technologies. Thermal losses generated along the DH network $\left(\dot{\mathrm{Q}}_{1}\right)$ are included in the model and are approximated as shown in Eq. 18 . Specific constraints are added to make sure that the "Losses" unit is activated if and only if the DH network is used for a cluster. ${ }^{501}$

$$
\dot{\mathrm{Q}}_{1}=\mathrm{U} \cdot \mathrm{L}_{\mathrm{DH}} \cdot\left(\left(\mathrm{T}_{\text {supply }}-\mathrm{T}_{\text {ground }}\right)+\left(\mathrm{T}_{\text {return }}-\mathrm{T}_{\text {ground }}\right)\right)
$$

where $\mathrm{T}_{\text {ground }}$ is the ground temperature, $\mathrm{U}$ is the overall lin-506 ear heat transfer coefficient, $\mathrm{L}_{\mathrm{DH}}$ is the $\mathrm{DH}$ network length and507 $\mathrm{T}_{\text {supply }} / \mathrm{T}_{\text {return }}$ are the supply/return temperatures of the $\mathrm{DH}$ net-508 work.

The different resources, technologies and demands are de-510 fined as "units" (u). U corresponds to the set of units of the511 entire system. Each unit has inputs and outputs, which can ${ }^{512}$ be thermal, electrical or mass flows. The model is based on ${ }^{513}$ the formulation in [42], in which more details are available. A514 multiperiod expression dividing the year in four periods (win-515 ter, mid-season, summer, peak) is adopted in order to account 516 for seasonality. Thus, the temporal fluctuations in the building517 heating demand are included in the analysis. For each building 518

\footnotetext{
${ }^{5}$ Personal communication with the CADOUEST company [45]
} 521 and each period, the average heating power demand is considered. The peak period represents the extreme conditions and it is used for the sizing of the energy technologies.

The general MILP model formulation is expressed as follows:

$$
\begin{aligned}
& \min C_{t o t}=\sum_{\mathrm{u} \in \mathrm{U}}\left(C_{i n v}(\mathrm{u})+\sum_{\mathrm{t} \in \mathrm{T}} C_{o p}(\mathrm{u}, \mathrm{t})\right) \\
& \text { s.t. } \quad \operatorname{Use}_{t}(\mathrm{u}, \mathrm{t}) \geq \mathrm{use}_{\mathrm{f}}(\mathrm{u}, \mathrm{t}) \\
& \forall \mathrm{u} \in \mathrm{U}, \forall \mathrm{t} \in \mathrm{T} \\
& \mathrm{f}_{\min }(\mathrm{u}) U s e_{t}(\mathrm{u}, \mathrm{t}) \leq \operatorname{Mult}_{t}(\mathrm{u}, \mathrm{t}) \leq \mathrm{f}_{\max }(\mathrm{u}) U s e_{t}(\mathrm{u}, \mathrm{t}) \\
& \forall \mathrm{u} \in \mathrm{U}, \forall \mathrm{t} \in \mathrm{T} \\
& U_{s e}(\mathrm{u}, \mathrm{t}) \leq U s e(\mathrm{u}) \\
& \forall \mathrm{u} \in \mathrm{U}, \forall \mathrm{t} \in \mathrm{T} \\
& \operatorname{Mult}_{t}(\mathrm{u}, \mathrm{t}) \leq \operatorname{Mult}(\mathrm{u}) \\
& \forall \mathrm{u} \in \mathrm{U}, \forall \mathrm{t} \in \mathrm{T} \\
& C_{\text {inv }}(\mathrm{u})=\mathrm{c}_{\text {inv,fix }}(\mathrm{u}) U \operatorname{se}(\mathrm{u})+\mathrm{c}_{\text {inv,var }}(\mathrm{u}) \operatorname{Mult}(\mathrm{u}) \\
& \forall \mathrm{u} \in \mathrm{U} \\
& C_{o p}(\mathrm{u}, \mathrm{t})=\left(\mathrm{c}_{\mathrm{op}, \text { fix }}(\mathrm{u}) U s e_{t}(\mathrm{u}, \mathrm{t})+\mathrm{c}_{\mathrm{op}, \mathrm{var}}(\mathrm{u}) \operatorname{Mult}_{t}(\mathrm{u}, \mathrm{t})\right) \mathrm{t}_{\mathrm{op}}(\mathrm{t})
\end{aligned}
$$

$\forall \mathrm{u} \in \mathrm{U}, \forall \mathrm{t} \in \mathrm{T}$

$\sum_{\mathrm{u} \in \mathrm{U}_{\mathrm{c}}} \dot{\mathrm{q}}_{\text {in }}(\mathrm{u}, \mathrm{t}, \mathrm{l}) \operatorname{Mult}_{t}(\mathrm{u}, \mathrm{t})-\sum_{\mathrm{u} \in \mathrm{U}_{\mathrm{c}}} \dot{\mathrm{q}}_{\text {out }}(\mathrm{u}, \mathrm{t}, \mathrm{l}) \operatorname{Mult}_{t}(\mathrm{u}, \mathrm{t})=0$

$\forall \mathrm{t} \in \mathrm{T}, \forall \mathrm{l} \in \mathrm{L}, \forall \mathrm{c} \in \mathrm{C}$

$\sum_{\mathrm{u} \in \mathrm{U}} \dot{\mathrm{m}}_{\mathrm{res}, \mathrm{in}}(\mathrm{u}, \mathrm{t}, \mathrm{res}) \operatorname{Mult}_{t}(\mathrm{u}, \mathrm{t})$

$-\sum_{\mathrm{u} \in \mathrm{U}} \dot{\mathrm{m}}_{\mathrm{res}, \text { out }}(\mathrm{u}, \mathrm{t}, \mathrm{res}) \operatorname{Mult}_{t}(\mathrm{u}, \mathrm{t})=0$

$\forall \mathrm{t} \in \mathrm{T}, \forall$ res $\in$ Res

The objective of the MILP model is to minimize the total annual cost of the entire energy system $\left(C_{t o t}\right)$, which is the sum of the total annualized investment $\left(C_{i n v}\right)$ and of the yearly operating cost $\left(C_{o p}\right)$ of the units $(\mathrm{Eq}, 19)$. The investment cost is linearized as the summation of two components, $c_{\text {inv, fix }}$ and $c_{\text {inv,var }}$ $(\mathrm{Eq} 24) . c_{\text {inv,fix }}$ is the fixed investment cost, activated if the unit is purchased while $c_{\text {inv,var }}$ is the variable cost associated to the size of the unit. In the same way, the operating cost is linearized as the summation of two components, $\mathrm{c}_{\mathrm{op} \text {,fix }}$ and $\mathrm{c}_{\mathrm{op}, \mathrm{var}}(\mathrm{Eq} 25)$. $c_{o p, f i x}$ is the fixed operating cost activated if the unit is operated in a period while $c_{\mathrm{op} \text {,var }}$ is the variable operating cost associated with the size of the unit output in a given period.

The binary variable $U s e_{t}$ defines the use of a unit in a given period. If $U s e_{t}(\mathrm{u}, \mathrm{t})=0$ the unit $\mathrm{u}$ is not used during the period $\mathrm{t}$ while if $U s e_{t}(\mathrm{u}, \mathrm{t})=1$ the unit is used. The binary parameter use $\mathrm{f}_{\mathrm{f}}$ can force the use of a unit in a given period (Eq 20). The utilization rate at which a unit is operated in a given period is defined by the variable Mult $_{t}$. Unit inputs and outputs are defined for the default size of the unit and are proportionally scaled based on the value of this variable. The parameters $f_{\min }(u)$ and $f_{\max }(u)$ represent the minimum and the maximum size of 
the unit u respectively (Eq 21). A unit is called "process" if use $_{f}(u, t)=f_{\min }(u)=f_{\max }(u)=1$, otherwise it is called "utility". The variables Use and Mult are associated with the investment decision. They consider the decisions of purchasing the unit (Eq 22) and the installed size (Eq23) according to the default size, respectively.

The thermal flows are separated into different categories in order to ensure realistic exchanges. For example, a thermal flow exiting a centralized unit cannot directly supply the consumers, as it has to pass through a DH network beforehand. Thus, the output thermal flow exiting the centralized unit and the input thermal flow entering the DH network belong to the same category. The set including the different categories is called L with reference to the concept of Layers as in [42]. The thermal power balance is respected independently in each cluster $\mathrm{c} \in \mathrm{C}$ and for each period (Eq 26). Differently from [42], there576 is no heat cascade in this formulation. Heat is just treated as $a^{577}$ first principle energy balance, divided into temperature levels. ${ }^{578}$ $\mathrm{U}_{\mathrm{c}}$ corresponds to the set of units included in the cluster $\mathrm{c}$. The ${ }^{579}$ parameters $\dot{q}_{\text {out }}$ and $\dot{q}_{\text {in }}$ are the default thermal powers which ${ }^{580}$ are delivered and required by the units, respectively. As a sim-581 plification, the mass flow rate variations in the DH network are582 not considered in the MILP model. However, a further analysis ${ }^{583}$ including the flow rates in the pipelines is essential for inves-584 tigations more focused on the operational aspects of the $\mathrm{DH}^{585}$ network.

On the other hand, the mass/electrical flow balance is ${ }^{587}$ respected over the whole system for each period (Eq 27).588 $\dot{\mathrm{m}}_{\text {res,out }}(\mathrm{u}, \mathrm{t}, \mathrm{res})$ is the default input flow of the resource res re-589 quired for a unit, whereas $\dot{\mathrm{m}}_{\mathrm{res}, \text { out }}(\mathrm{u}, \mathrm{t}, \mathrm{res})$ is the default output ${ }^{590}$ flow from a unit.

\section{Results: the case study of a geothermal resource}

\subsection{Presentation of the case study.}

The approach is applied to the integration of a geothermal597 resource in the city of Lausanne (Switzerland, 140'421 inhab-598 itants in 2015) which is taken as an example case study. The599 total heating demand of the city is estimated to be $1660.4 \mathrm{GWh}^{600}$ in 2012, representing $59 \%$ of the total final energy demand601 [31]. An existing DH network, supplying about $21 \%$ of the602 city's heating demand in 2012, is powered by a Municipal Solidoo3 Waste Incineration (MSWI) power plant $(60 \%)$, fossil fuels 604 such as gas and heating oil (36.2\%), and a Waste Water Treat-605 ment Plant (WWTP) $(3.8 \%)$ [31]. The projected expansionoo6 of the DH network offers an opportunity for the integration of 607 geothermal energy. A Malm aquifer is located under the cityoos and could be exploited as a heat resource for direct heat supply.609 The temperature of the Malm aquifer is estimated to be $65^{\circ} \mathrm{C} 610$ and the expected mass flow rate is $25 \mathrm{~kg} / \mathrm{s}$ [25]. Figure 9 shows611 the geothermal DH system modeled in the framework of this ${ }^{612}$ case study. This simplified geothermal system configuration is based on the DH case of Riehen [29] where the geothermal re-613 source has similar characteristics to the one in Lausanne. $\quad{ }_{614}$

The supply and return temperatures of the DH network dur-615 ing summer are assumed to be $60^{\circ} \mathrm{C}$ and $45^{\circ} \mathrm{C}$ respectively. $\mathrm{In}_{616}$

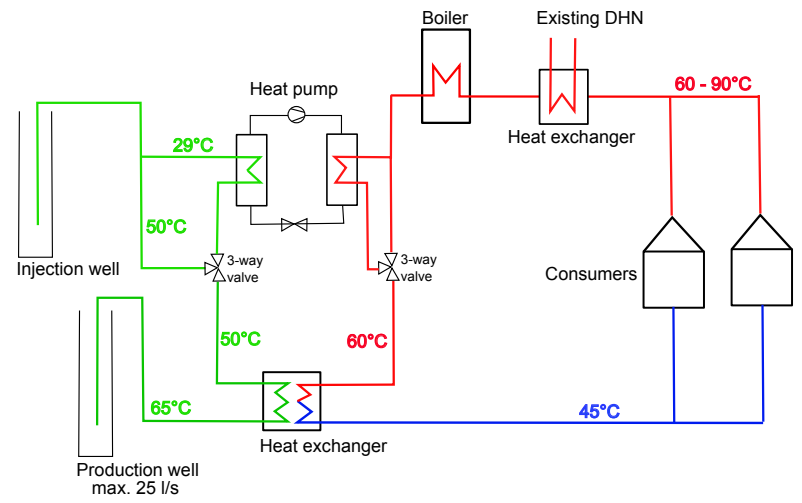

Figure 9: Schema of the energy system installation.

colder periods, the supply temperature is expected to increase up to $90^{\circ} \mathrm{C}$ whereas the return temperature is assumed constant over the year. The supply temperature conditions ensure that the total heat demand (SH and DHW) is met all year round. The minimum supply temperature is fixed at $60^{\circ} \mathrm{C}$ to satisfy DHW demand [39].

The geothermal fluid is pumped from a production well and is re-injected into the ground after delivering heat to the consumers. The geothermal system configuration depends on the temperature of the fluid and on the nature of the heating application. In this case, as shown in Figure 9 heat extraction from the fluid is performed in sequence by firstly exchanging heat directly and then passing through the evaporator of a heat pump. The amount of heat which can be extracted by means of the primary heat exchanger is limited by the return temperature of the network. Heat pumps are used to recover the part of heat which cannot be recovered by direct exchange, i.e. when the geothermal fluid reinjection temperature is lower than the return temperature of the network. This system configuration allows to fully exploit the geothermal resource. Thus, the heat pump assists the primary heat exchanger, supplying additional heat from the fluid and completely exploiting the resource. The maximum thermal power delivered from the aquifer is estimated to be $3^{\prime} 780 \mathrm{~kW}_{\text {th }}$ [25], cooling $25 \mathrm{~kg} / \mathrm{s}$ of pumped water from $65^{\circ} \mathrm{C}$ to $29^{\circ} \mathrm{C}$. Only a part of this thermal power is used in summer. On the other hand, in winter the demand is higher than the heat available from the geothermal well. A centralized natural gas boiler is included in the DH system in order to satisfy the higher demand in these months. A DH network already exists in Lausanne. The option of connecting the new DH networks to the existing network is considered by means of an additional heat exchanger. According to [31], the existing MSWI of Lausanne produces a heat excess during summer. Around $97 \mathrm{GWh}$ per year are used today in the second stage of the condensing turbine of the MSWI to produce electricity with very low efficiency. This excess heat could be more reasonably used for heating instead of electricity production.

\subsection{Data collection}

The annual SH and DHW demand of the buildings of Lausanne ( $\mathrm{Q}_{\mathrm{SH}}$ and $\mathrm{QHW}_{\mathrm{HW}}$ respectively) are provided by the center of energy research of Martigny (CREM), Switzerland [37]. From 
this data, the seasonal average SH power demands of the build-653 ings are estimated based on the seasonal distribution of the heat-654 ing demand presented in [31] for the buildings of Lausanne. It is assumed that there is no SH in summer. More information concerning the evaluation of these seasonal heating demands is available in the ESI. Additionally, the CREM provided the geographical coordinates of the buildings. This data is based on the federal register of buildings and accommodations [44].

Seismic investigations performed during the last decades provide a good geological characterization of Lausanne. The Malm's depth estimations (varying between 1'400 m and 1'900 $m$ over the whole city) were provided by the Laboratory of Soil Mechanics (LMS, EPFL) with an horizontal resolution of 20 $\mathrm{m}$ [27]. The latter allows an evaluation of the spatial distribution of the drilling investment costs over the whole urban area, assuming the use of 2 wells (production and injection wells). Figure 10 shows that investment costs range between 6.23 MCHF and 9.43 MCHF. The lowest drilling cost is located on the southwest area of the city whereas the maximum is ${ }^{65}$ found on the northeast side. The cost evaluation was performed ${ }^{65}$ in this study using the software GEOPHIRES developed at the ${ }^{657}$ Cornell Energy Institute [38].

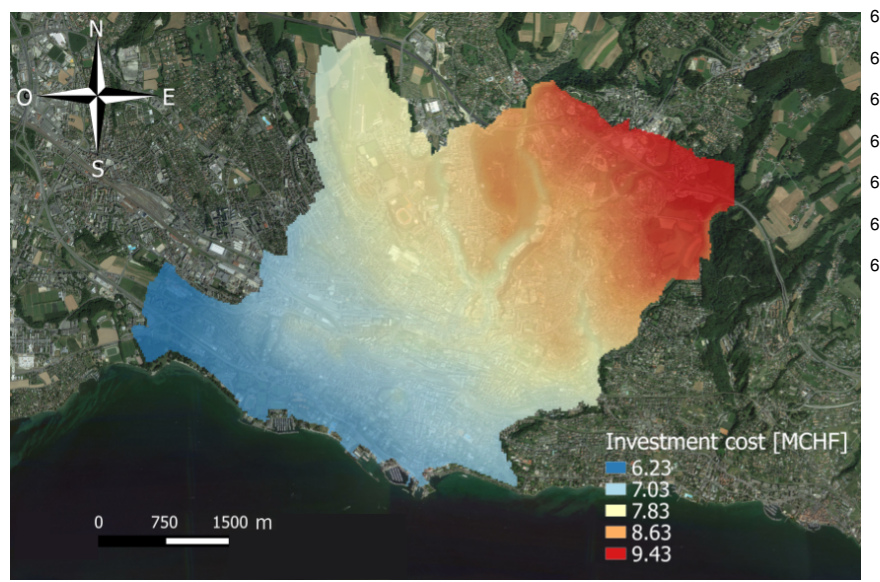

Figure 10: Drilling investment costs (2 wells) mapped over the City of Lausanne. The color distribution shows the corresponding investment costs for each location in the city. Satellite image: Landsat 7 image, 2016.

The georeferenced road network of the city of Lausanne was provided by the "OpenStreetMap contributors (c) http://www.openstreetmap.org/".

\subsection{Spatial clustering}

The clustering method is applied to the 6'224 buildings which are not yet connected to the existing DH network. As discussed in section 2.2.1, a high number of subclusters improves ${ }^{667}$ the quality of the ILP clustering step. Thus, the ILP model has ${ }^{668}$ been tested using different numbers of subclusters in order to ${ }^{669}$ assess the corresponding computational needs and define the ${ }^{670}$ maximum number of subclusters to be generated for this case study. The available computational resources used for the tests are limited to one compute node including 2 processors running at $2.2 \mathrm{GHz}$ with 8 cores each and $32 \mathrm{~GB}$ of RAM. Figure
11 presents the CPU time and the maximum memory required for the branch\&cut tree against the number of subclusters.

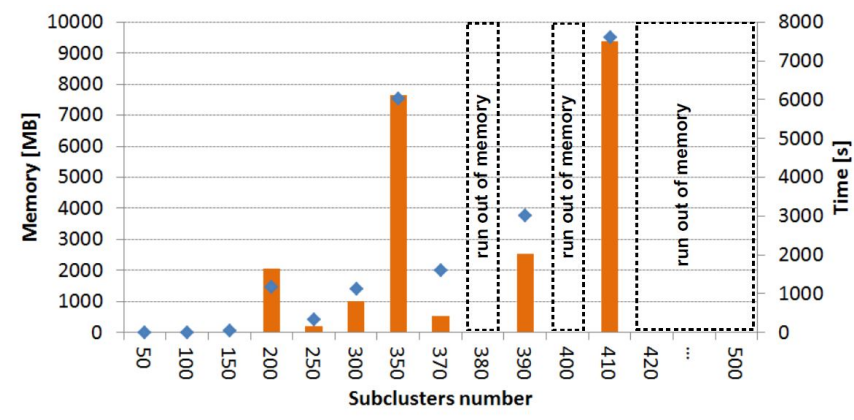

nax. memory required for the branch\&cut tree - Solving elapsed time

Figure 11: Solving elapsed time and memory requirement of the ILP process with different numbers of subclusters.

Figure 11 highlights significant and quite irregular variations in time and memory depending on the number of subclusters. Small variations in the number of subclusters can lead to large variations in terms of needed computational resources. In general, despite some oscillations, time and memory increase with the number of variables. The resolution of the model is limited by the memory requirements and not by the solving elapsed time. Even if the memory requirements exceed the available 32 GB with 380 and 400 subclusters, the model can be solved with 410 subclusters 6 Thus, the number of subclusters $N_{s}$ is set to 410 . Figure 12 presents the resulting subclusters formed by 6'224 buildings grouped into 410 subclusters.

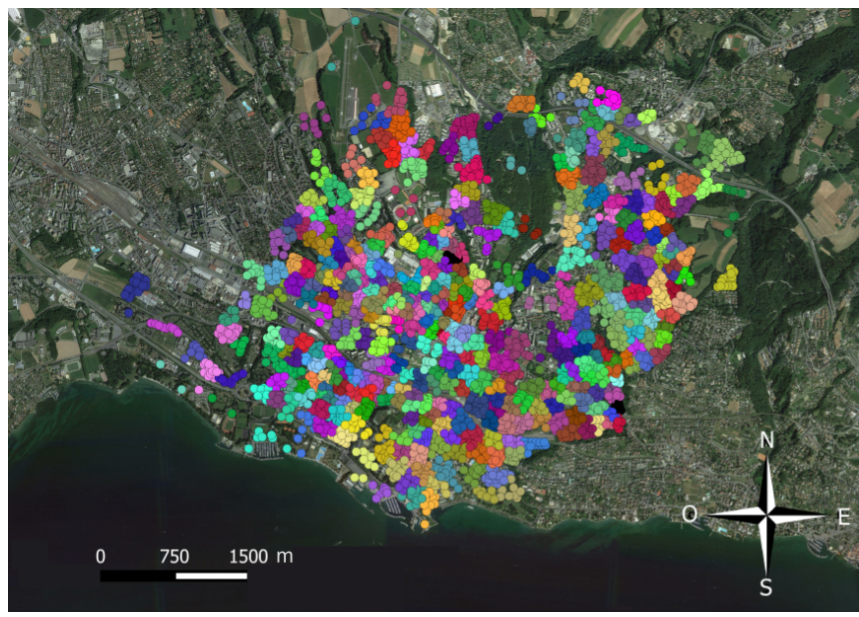

Figure 12: The buildings of the city represented as points and grouped in 410 subclusters. Satellite image: Landsat 7 image, 2016.

The ILP model was run with and without the two added constraints presented in Eq. 6 and in Eq. 7. Figure 13 shows the required computational time with different number of subclusters in the two cases. It is demonstrated that the saving of

\footnotetext{
${ }^{6}$ In case the preliminary clustering is not applied, the number of buildings used for the ILP would be 6'224. This situation can not be solved as the problem complexity increases with $n^{2}$.
} 
computational time is significant by adding the constraints. As an example, the computational time is reduced by a factor of 5.3 for 170 sublusters.

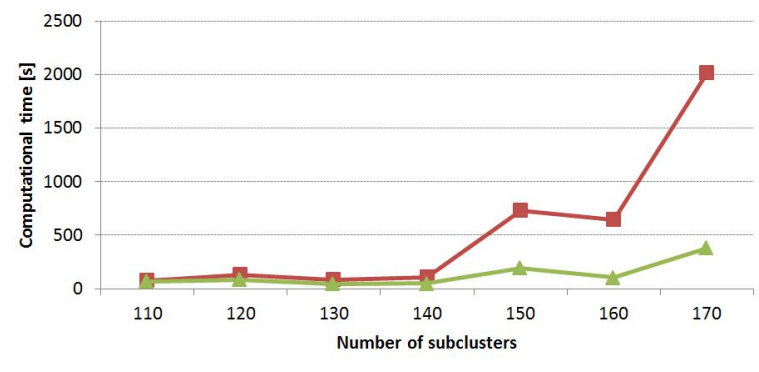

$\rightarrow-$ Without the constraints $\rightarrow$ With the constraints

Figure 13: Required computational time with and without the added constraints presented in Eq. 6 and in Eq. 7

The definition of the bounds $v_{\min }$ and $v_{\max }$ depends on the availability and the exploitation mode of the energy resource. The size of clusters is adapted to the power available from the geothermal well. Geothermal facilities have high investment costs and their economics depend strongly on the amount of heat extracted from the geothermal fluid. The SH demand of buildings fluctuates significantly over the year. Geothermal installations sized to meet peak demand are under-utilized. Einarsson [40] showed the advantages of using geothermal facilities as baseload to overcome this problem. A baseload power demand corresponds to a heating power demand which is ${ }_{717}$ constant over the whole year. However, to our knowledge there are no clear design rules for sizing the centralized geothermal facilities given the seasonal distribution of heat loads. Existing geothermal case studies showed that differences in resource conditions and in heating demand can lead to different system designs. Harrison [39] presented two alternative design options based on real case studies: the full coverage and the partial coverage approaches.

1. In the cases of low drilling costs and spatially dispersed heat demand involving high connection costs, it is economically more interesting to size geothermal based on peak demand. This approach is called the full coverage approach. It is typically found in the US where thermal gradients are high and thus high well head temperatures are common as shown in the Figures 14a and 14b Indeed, this approach implies that the geothermal well is oversized for periods of low heat demand.

2. In the cases of high drilling costs and spatially concen- ${ }_{72}$ trated heat demand involving lower connection costs, it is ${ }_{722}$ economically more interesting to size the geothermal well $1_{723}$ based on baseload demand. This approach is called the $\mathrm{e}_{724}$ partial coverage approach. It occurs for example in France $_{725}$ where the thermal gradients and the well head tempera- ${ }_{726}$ tures are lower as shown in the Figures 14a and 14b

In Lausanne the outdoor temperature varies significantly over ${ }^{728}$ the year. Thus, heat loads fluctuate along a wide range of values (from 78.5 $\mathrm{MW}_{\text {th }}$ up to 523.1 $\mathrm{MW}_{\text {th }}$ during the peak period [31]). The geothermal resource conditions in Lausanne are ${ }_{729}$

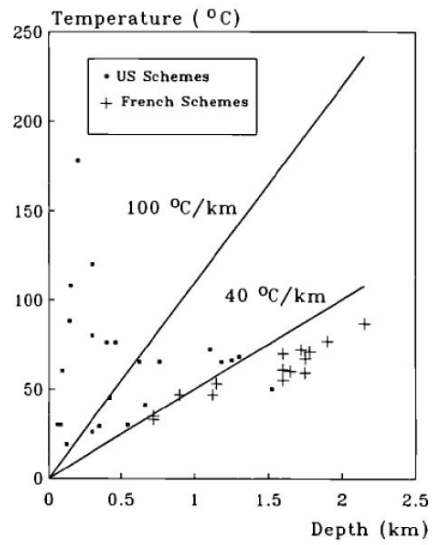

(a)

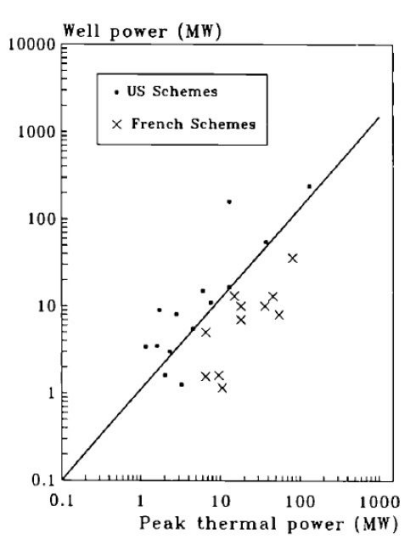

(b)
Figure 14: Different geothermal well installations in the USA and in France. Figure 14a shows the relationship between well head temperatures and well depths for several US and French geothermal heating facilities [39]. Figure $14 \mathrm{~b}$ shows the relationship between theoretical well powers and peak power demands for some US and French geothermal installations. The theoretical well power is calculated from well head temperature, production flow and an assumed return temperature of $40^{\circ} \mathrm{C}$ [39].

similar to the ones observed in France. The spatial heat demand density is considered as concentrated. These observations justify the choice of the partial coverage approach. This decision is supported by the geothermal DH system of Riehen, where the partial approach was also applied [29]. Based on [39] and [29], Figure 15 shows typical heating load curves of a heat pump assisted geothermal installation in a partial coverage approach.

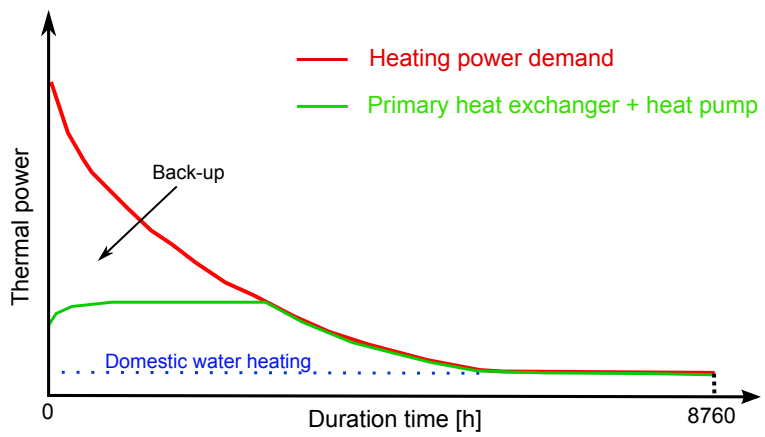

Figure 15: Typical heating load curves of a heat pump assisted geothermal installation in a partial coverage approach.

In the present case study, it is assumed that the heat load of DHW, constant over the whole year, is directly satisfied by the heat extraction across the primary heat exchanger. Thus, the parameter $v_{\max }$ in the ILP model is set to the maximum thermal power extracted across the primary heat exchanger $\left(\dot{\mathrm{Q}}_{\mathrm{HE}, \max }\right)$ minus the thermal losses occurring along the DH network $\left(\dot{\mathrm{Q}}_{1}\right)$ as shown in Eq. 28. Based on existing data about the DH network of the city of Lausanne, the thermal losses in summer are set equal to $30 \%$ of the heat production.

$$
v_{\text {max }}=\dot{\mathrm{Q}}_{\mathrm{HE}, \text { max }}-\dot{\mathrm{Q}}_{\mathrm{l}} \approx \dot{\mathrm{Q}}_{\mathrm{HE} \text {,max }}-0.3 \cdot \dot{\mathrm{Q}}_{\mathrm{HE} \text {,max }}
$$

As shown in Eq. 29. $\dot{\mathrm{Q}}_{\mathrm{HE}, \max }$ is a function of the maximum 


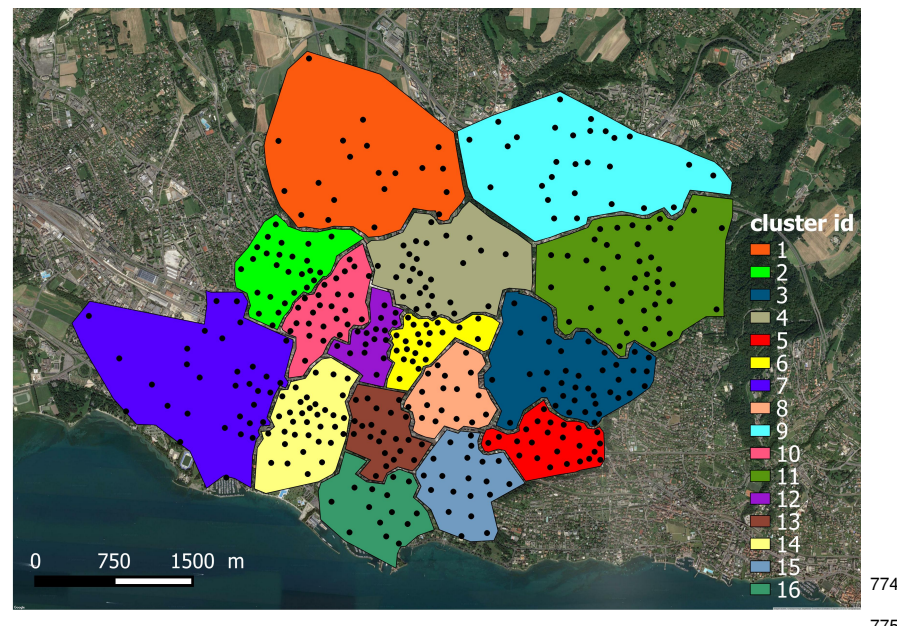

Figure 16: Spatial configuration of the resulting clusters. The centroids of sub-776 clusters are represented by black points. Even if the DHW heating demand is similar in each cluster, their size vary significantly according to their location. ${ }^{777}$ The spatial density of the DHW heating demand is higher in the city center. ${ }^{778}$ Satellite image: Landsat 7 image, 2016. mass flow of the geothermal fluid (m), the specific heat capacity762 of water at constant pressure $\left(c_{p}\right)$ and the temperature difference ${ }_{763}$ of the fluid between the inlet and outlet of the heat exchanger 764 $\left(\Delta \mathrm{T}_{\text {geo, } \mathrm{HE}}=65^{\circ} \mathrm{C}-50^{\circ} \mathrm{C}\right)$.

$$
\dot{\mathrm{Q}}_{\mathrm{HE}, \max }=\dot{\mathrm{m}} \cdot \mathrm{c}_{\mathrm{p}} \cdot \Delta \mathrm{T}_{\mathrm{geo}, \mathrm{HE}}
$$

According to Eq. 13 and Eq. 28, $v_{\max }$ and $v_{\min }$ are set equal ${ }^{768}$ to $1^{\prime} 098 \mathrm{~kW}_{\text {th }}$ and 1 '054 $\mathrm{kW}_{\text {th }}$ respectively. This assumes ideal ${ }^{769}$ heat exchanges. Thus, the cluster sizing is based on the sum- ${ }^{770}$ mer conditions and the geothermal well is oversized compared ${ }^{771}$ to the heating demand in summer by a minimum factor of 3.44 . $^{772}$ This factor is the ratio between the maximum thermal power ${ }^{773}$ which can be delivered by the geothermal fluid (3'780 $\mathrm{kW}_{\mathrm{th}}$ ) and $v_{\max }\left(1 ' 098 \mathrm{~kW}_{\mathrm{th}}\right)$. This result is coherent with the heating load curves of the geothermal installation in Riehen [29] and with the results in [39]. The parameters set $\mathrm{P}$ presented in $\mathrm{Eq} 12$ corresponds to the DHW demand of the buildings, which is considered constant over the year. Figure 16 presents the territorial configuration of the 16 clusters resulting from the ILP process.

\subsection{DH network length estimation}

In order to compare the validity of the DH length estimation ${ }^{783}$ presented in section 2.3 with real cases, the methods are applied ${ }^{784}$ to a set of 399 buildings currently connected to the existing $\mathrm{DH}^{785}$ network. This comparison is shown in Figure 17. Figure $17 \mathrm{a}{ }^{36}$ shows the existing DH network connecting the buildings. Its to- ${ }^{787}$ tal length is $23^{\prime} 235 \mathrm{~m}$. This length is exclusively based on the latitudinal and longitudinal coordinates. Variation in altitude is 788 not considered here. Figure $17 \mathrm{~b}$ shows the modeled DH network configuration. Its total length is $24^{\prime} 132 \mathrm{~m}, 3.7 \%$ higher $^{789}$ than the real one. This is explained by the imperative usage of ${ }^{790}$ the roads network for the pipelines. Detours are unavoidable if the DH network is forced to follow the roads. As an example, the black arrow in Figure $17 \mathrm{~b}$ shows a typical detour implied by the routing method. Moreover, the map of the real DH network provided by the city is not precise enough since some buildings are not perfectly connected to the network. On the other hand, if the Johnson's algorithm is skipped in the methodology steps and Euclidean distances between the buildings are considered instead, the total length of the modeled DH network is only $13^{\prime} 482 \mathrm{~m}$. This highlights the importance of the routing algorithm. Thus, forcing the pipeline networks to follow the roads offers a good approximation of the real DH network length. For comparison, the method developed by Girardin et al. [11] is applied on the example buildings set and a total length of 9'629 $\mathrm{m}$ is computed 7

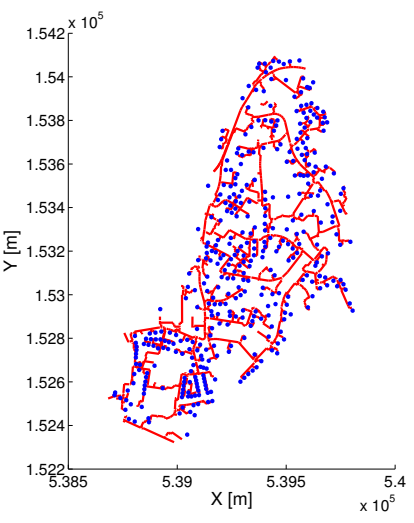

(a) Existing DH network

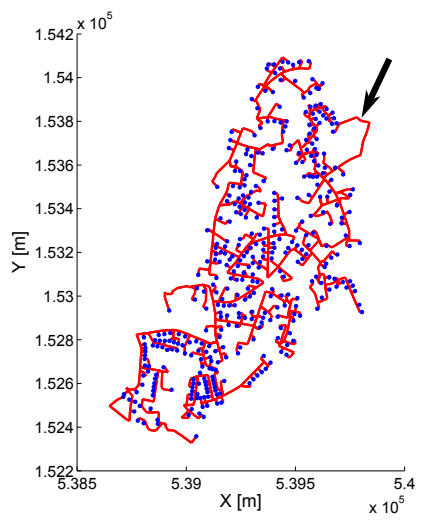

(b) Modeled DH network
Figure 17: Comparison between the existing DH network and the modeled DH network. Blue points represent the buildings while the red lines represent the network pipelines. The length of the existing network (a) is 23'235 m. The length of the modeled network (b) is $24^{\prime} 132 \mathrm{~m}$. The black arrow shows a typical detour implied by the routing method.

As an example, Figure 18 shows the spatial configuration of the DH network modeled in cluster 2. It illustrates the fact that the modeled DH network is forced to follow the roads. In addition, detours are also observed for the two southernmost buildings.

The DH network lengths of all clusters are available in the ESI.

The specific lengths are calculated on the basis of the DH lengths. The specific length of a cluster is defined as the ratio between its DH network length and its DHW demand. The spatial distribution of the specific lengths is presented in Figure 19. The latter highlights low specific lengths in the clusters $\mathrm{c}_{6}$, $\mathrm{c}_{8}, \mathrm{c}_{12}, \mathrm{c}_{13}$ and $\mathrm{c}_{16}$. This is explained by the higher building density in the city center.

\subsection{Cluster-oriented urban energy system modeling}

Figure 20 presents the cluster-oriented urban energy system model developed for the case study.

${ }^{7}$ The topological factor of 0.23 is used. This is the default value available in [11] calculated for the City of Geneva, Switzerland. 


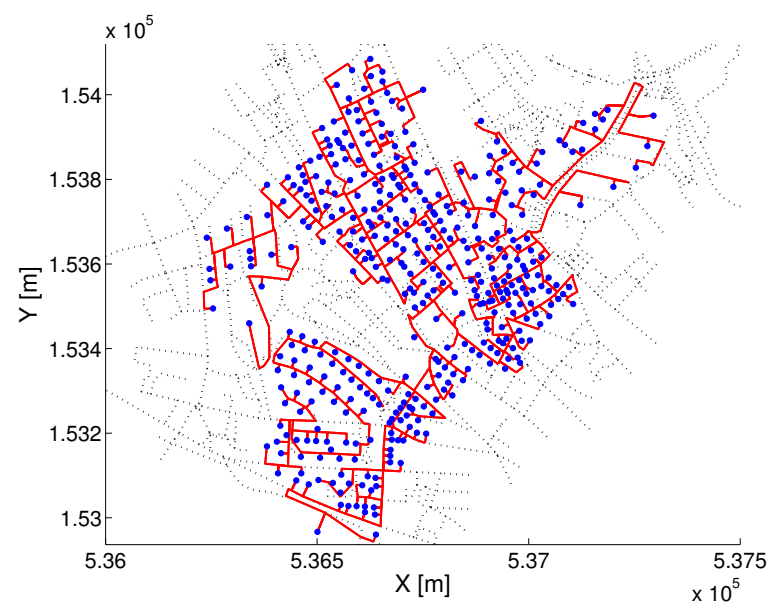

Figure 18: The configuration of the DH network modeled in the cluster 2 . The blue points represent the buildings while the red lines represent the network pipelines. The black dotted lines correspond to the road network.

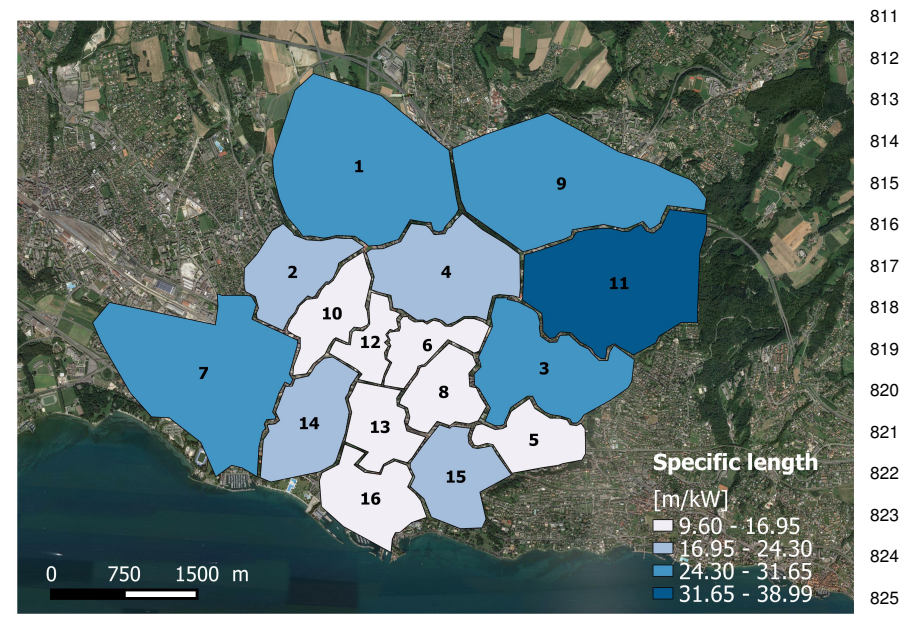

Figure 19: Map of the specific lengths of the clusters. The cluster id is displayed on the polygons. Satellite image: Landsat 7 image, 2016.

The energy resources are of two types: imported and indige- ${ }^{827}$

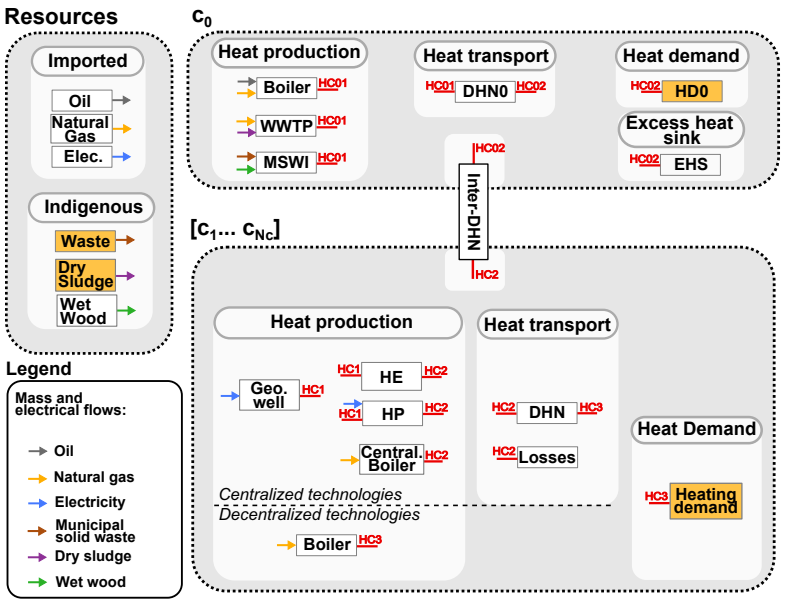

Figure 20: Superstructure of the whole urban heating system.

(HP), a centralized natural gas boiler (Central. Boiler), a decentralized natural gas boiler (Boiler), a DH network (DHN), thermal losses (Losses), an interconnection DH network (InterDHN) and the heating power demand including SH and DHW. The unit parameters are available in the ESI. The different categories for the thermal flows are denoted "HC"in Figure 20 The drilling investment costs of the wells are averaged over the area of each cluster based on the data presented in Figure 10 . The maximum heat transfer capacity of the primary heat exchanger is fixed to 1'569 $\mathrm{kW}\left(\dot{\mathrm{Q}}_{\mathrm{HE}, \max }\right)$, as in Eq. 29. The main parameter of the heat pump is the ratio between the energy output (heat delivered) over the energy input (electricity), named the coefficient of performance (COP). The COP depends on the operating conditions (temperature difference). The relationship between the heat load delivered $\dot{\mathrm{Q}}_{\mathrm{h}}^{-}$, the electricity consumed $\dot{\mathrm{E}}_{\mathrm{el}}^{+}$and the $\mathrm{COP}$ is given in Eq. 30

$$
\dot{\mathrm{Q}}_{\mathrm{h}}^{-}=\mathrm{COP} \cdot \dot{\mathrm{E}}_{\mathrm{el}}^{+}
$$

The real COP is expressed as a ratio of temperatures as shown in Eq. 31 .

$$
\mathrm{COP}=\frac{\mathrm{T}_{\mathrm{h}}}{\mathrm{T}_{\mathrm{h}}-\mathrm{T}_{\mathrm{c}, \mathrm{lm}}} \cdot \eta
$$

where $T_{h}$ is the temperature at the condenser (temperature at the $\mathrm{DH}$ network), $\mathrm{T}_{\mathrm{c}, \mathrm{lm}}$ is the $\log$ mean temperature at the evaporator (temperature of the geothermal fluid) and $\eta(0.45)$ is the cycle's second law efficiency compared to an ideal cycle.

The centralized natural gas boiler is used as a back-up in periods of high heating demand as shown in Figure 15 . The decentralized natural gas boilers are aggregated and represented by one unit. The price of the gas is fixed at $111.14 \mathrm{CHF} / \mathrm{MWh}^{8}$ It has to be noted that the considered gas price is quite high. The thermal losses $\dot{\mathrm{Q}}_{1}$ generated along the DH networks are computed based on Eq. 18 presented in the methodology. The

\footnotetext{
${ }^{8}$ This price corresponds to a reference gas price for the year 2050 [41]. It is assumed that the price for the City of Lausanne is twice the import price at the Swiss borders [42].
} 


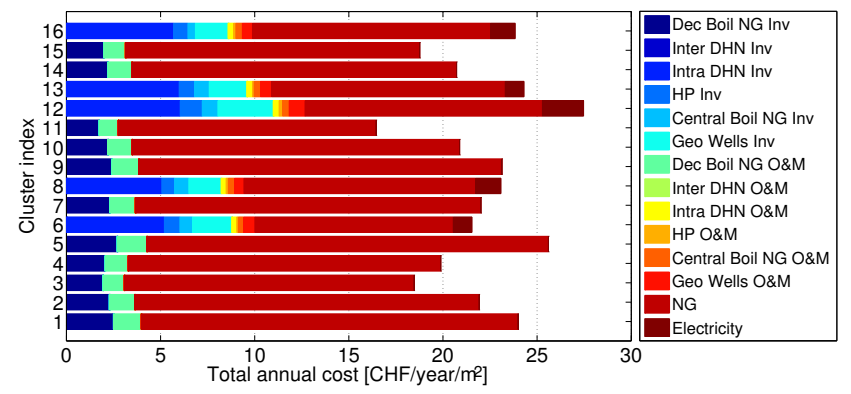

Figure 21: Distribution of the total annual cost per square meter of heated floor ${ }^{897}$ space in the different clusters. For each technology, the investment cost (Inv) ${ }^{898}$ and the operating cost (O\&M) are represented independently. NG and Decses mean natural gas and decentralized respectively. Intra DHN is the network $\mathrm{in}_{900}$ each cluster.

parameters $T_{\text {ground }}$ and $U$ are defined as follows: $T_{\text {ground }}$ is as-875 sumed constant over the year and equal to $10^{\circ} \mathrm{C}, \mathrm{U}$ is assumed 876 to be equal to $0.295 \mathrm{~W} / \mathrm{K} / \mathrm{m}^{9}$

Each cluster can receive the excess heat from $\mathrm{c}_{0}$ through $\mathrm{h}_{88}$ the unit "Inter-DHN". The latter represents additional network879 pipelines connecting the existing DH network and the poten-880 tial new ones. The length of the "Inter-DHN" unit included in 881 $c_{k}$ is defined as the shortest Euclidean distance that can be ob-882 served between a building of $\mathrm{c}_{0}$ and a building of $\mathrm{c}_{\mathrm{k}}$. The Eu-883 clidean distance is chosen here as a simplification. Heat trans-884 fers among the clusters $c_{1}-c_{16}$ are not permitted in the cluster-885 oriented energy system model. This is motivated by the fact that ${ }_{886}$ in the clustering process the heat demand of each cluster is con-887 strained to match the heat availability of the geothermal well.s88 In this way, one geothermal well can satisfy the heat demand of 889 one and only one cluster.

Figure 21 presents the results of the optimization. The to-891 tal annual costs per square meter of heated floor space is dis-892 tributed among the different technologies for each cluster. Thes93 costs of the cluster $c_{0}$ do not appear as they refer to an exist-894 ing system, and thus they represent a fixed component in the objective function. Results show that it is economically more profitable to install DH systems in clusters $\mathrm{c}_{6}, \mathrm{c}_{8}, \mathrm{c}_{12}, \mathrm{c}_{13}$ and $c_{16}$. This is in line with the specific lengths shown in Figure 19 The investment cost of the DH network in the centralized clusters represents an important part of the total annual cost $(23.3 \%$ on average). The cost related to the gas import represents on average $50.4 \%$ of the total annual cost for centralized cases. This corresponds to a reduction of $33 \%$ on average $e^{10}$ compared with the decentralized configurations.

In order to compare the benefits or the losses associated to ${ }_{902}^{903}$ the deployment of $\mathrm{DH}$ in each cluster, centralized and decen- ${ }_{904}$ tralized options are compared for each of the clusters. Figure ${ }_{905}$ 22 shows the total annual cost differences per square meter of ${ }_{906}^{905}$ heated floor space between optimal centralized and decentral- ${ }_{907}$ ized options. The differences vary between $-2.37 \mathrm{CHF} / \mathrm{yr} / \mathrm{m}^{2^{907}}$

\footnotetext{
${ }^{9}$ From discussion with the CADOUEST company, Lausanne.

${ }^{10}$ Based on a comparison centralized vs. decentralized scenarios for the five $\mathrm{e}^{911}$ clusters for which centralization is economically optimal.
}

and $8.4 \mathrm{CHF} / \mathrm{yr} / \mathrm{m}^{2}$. A negative (positive) value indicates that the total annual cost is higher (lower) with a decentralized configuration compared with a centralized one. It is economically profitable to install a DH system in the clusters $\mathrm{c}_{6}, \mathrm{c}_{8}, \mathrm{c}_{12}, \mathrm{c}_{13}$ and $c_{16}$. The greater benefits are offered by centralizing the heating systems of clusters $c_{8}$ and $c_{12}$ with $1.16 \mathrm{CHF} / \mathrm{yr} / \mathrm{m}^{2}$ and $2.37 \mathrm{CHF} / \mathrm{yr} / \mathrm{m}^{2}$, respectively. On the contrary, clusters $\mathrm{c}_{9}$ and $c_{11}$ are the least suitable for centralization involving cost increases of $8.4 \mathrm{CHF} / \mathrm{yr} / \mathrm{m}^{2}$ and $8.09 \mathrm{CHF} / \mathrm{yr} / \mathrm{m}^{2}$, respectively. Figure 23 shows the spatial distribution of these total annual cost differences. The most interesting areas for a new $\mathrm{DH}$ integration are generally located in the center and in the south of the city $\left(c_{6}, c_{8}, c_{12}, c_{13}\right.$ and $\left.c_{16}\right)$. This is explained by a shorter DH network length required in these zones, which is a consequence of the higher density of the heating demand. Moreover, the investment cost for the wells are lower in these zones as shown in Figure 10. This is mainly due to the lower depth of the aquifer in these areas. The application of the methodology to the example case study highlights the economical interest of geothermal energy for direct heat supply in some urban sites.

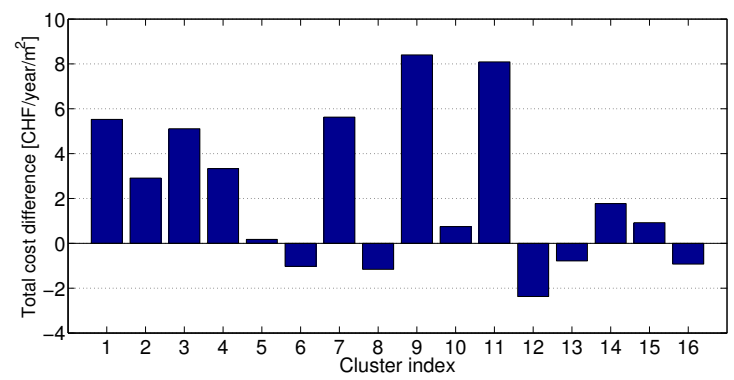

Figure 22: The total annual cost differences per square meter of heated floor space between optimal centralized and decentralized options for the different clusters. A negative/positive value indicates that the total annual cost is higher/lower with a decentralized configuration compared with a centralization.

\section{Discussion}

The methodology allows a rigorous clustering of an urban system based on optimization. Compared to other methods in the literature (e.g. $k$-means) the proposed ILP approach allows to fully control the clustering process. Moreover, the number of resulting clusters does not need to be fixed but it is a result of the optimization. The addition of case-specific constraints offers the possibility to adapt the zoning to the local conditions and objectives. As an example, in this work compact building clusters are defined by adjusting their sizes to the availability of a given resource. The set of constraints can be easily adapted to different applications. As an example, the proposed ILP clustering could be adopted for statistical analysis purposes.

Due to the high number of binary variables, a pre-clustering is proposed to reduce the ILP clustering problem size. Results highlight that the size of the ILP model is limited by the computational resources (memory requirements). Thus, the use of High-Performance Computing (HPC) is recommended in order 


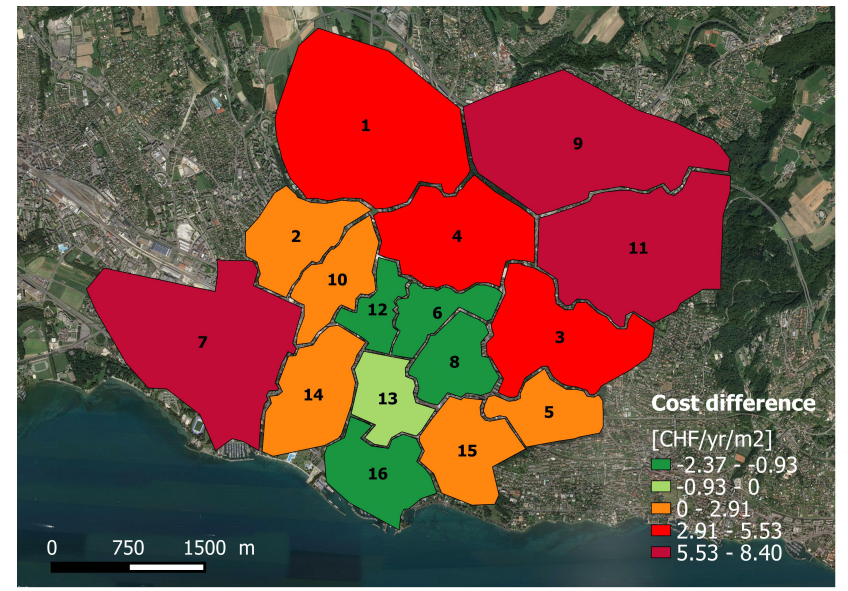

Figure 23: The spatial distribution of the difference in total annual cost ${ }^{96}$ per square meter of heated floor space between centralized and decentral- ${ }^{962}$ ized options. A negative/positive value indicates that the total annual cost is 963 higher/lower with a decentralized configuration compared with a centralization.964 Green color shows the zones where a centralization is economically attractive. ${ }_{965}$ Dark green color highlights the most interesting clusters. The cluster id is displayed on the polygons. Satellite image: Landsat 7 image, 2016.

to maximize the spatial resolution. Parallelization of the model ${ }_{968}$ on several compute nodes could be a future development.

Routing methods and graph theory allow to define a realis- ${ }^{969}$ tic DH network configuration in each cluster. The application ${ }^{970}$ of Johnson's and Kruskal's algorithms optimizes the network ${ }^{971}$ forcing the pipelines to follow the road network. Compared to ${ }^{972}$ an existing DH network, the proposed method obtains a rela- ${ }^{973}$ tive error of $3.7 \%$ in estimating the network length. The error ${ }^{974}$ is much lower in comparison to other methods proposed in the $\mathrm{e}^{975}$ literature (e.g. in [11]). The differences between the modeled ${ }^{976}$ DH network and the existing one can be explained by the fol- ${ }^{977}$ lowing reasons: the path of the modeled network must imper- ${ }^{978}$ atively follow the roads; connecting a building with its closest ${ }^{979}$ road segment can lead to detours in certain particular cases; in ${ }^{980}$ real cases, DH networks use a 'loop configuration' in order to ${ }^{981}$ be able to close some segments for maintenance without inter-982 ruption of the service. The proposed method does not consider ${ }^{983}$ the possibility of having loops in the network.

The methodology was applied to an example case study, eval- ${ }^{985}$ uating the integration of a geothermal energy resource. It is ${ }^{986}$ demonstrated in the case study that the definition of the param- ${ }^{987}$ eters $v_{\min }$ and $v_{\max }$ in the ILP model merit a thorough analysis. ${ }^{988}$ Differences in resource conditions and in heating demand can ${ }^{989}$ lead to different system designs. The proposed MILP urban en- ${ }^{990}$ ergy modeling approach offers the possibility to economically ${ }^{991}$ and spatially evaluate the integration of the resource. This can be performed since the heating demand of each cluster meets $s_{992}$ the potential of the resource. Thus, a specific DH network can be modeled in the different clusters. By comparing different993 options for heat supply (i.e. decentralized boilers), optimiza-994 tion identifies the most interesting sites for DH deployment.995 The results of the optimization show the interest of deploying996 geothermal DH in some of the clusters. The profitability of ${ }_{997}$ DH integration is strongly affected by the spatial density of the 998 heating demand.

Spatial analysis can be a precious visualization tool for urban energy planners. As an example, in this work GIS and maps are used to show the cluster configuration as well as detailed pipeline routes.

The generality of the methodology allows its application to other resources and case studies. As the needed input data are commonly available (e.g. for cities in Switzerland), the whole methodology is readily reproducible for other cities. The ILP clustering approach can be adapted to the specific local conditions of the cities. This means that it can be used with other energy resources. As an example, municipal solid waste is a typical energy resource that could be integrated in the ILP model as a municipal solid waste incinerator could be deployed everywhere in a city (non-spatially limited resource). The heating demand of the clusters would be defined by the available amount combination of graph theory and routing methods orks that are spatially constrained (e.g. by the road network). As an example, the method can be applied for the preliminary design of water supply or electricity networks.

\section{Conclusion}

A methodology for the spatial integration of DH networks in urban energy systems is proposed. Given georeferenced data of buildings, energy resource and road networks, the methodology allows the identification of promising sites for $\mathrm{DH}$ deployment.

An ILP approach is used to define a rigorous spatial clustering of urban systems. Routing methods and graph theory are used to model realistic and optimized DH configurations based on the road network. A MILP energy model allows the economic evaluation of DH integration in each cluster simultaneously over the whole urban area. The methodology is illustrated by the application case study of a geothermal energy resource for direct heat supply. The results show the interest of deploying a geothermal DH network in some areas of the city.

The inclusion of georefenced data in energy models is a promising perspective in urban energy planning, in particular for the preliminary evaluation and design of DH systems. This study proposes a methodology allowing the integration of georeferenced information while keeping the model within tractable sizes. Future developments could envision a parallelization of the clustering ILP model on several compute nodes in order to increase the available computational capacity. This would allow the integration of a higher number of binary variables and thus a higher accuracy.

\section{Acknowledgments}

This work was performed in the framework of the GEOTHERM2 project, co-founded by the Competence Center Energy and Mobility of the ETH Domain (CCEM) and the Competence Center Environment and Sustainability (CCES).

The authors would like to thank the FEE (Fonds pour l'efficacité énergétique) and the SIL (Services Industriels de 


\section{Glossary}

$\begin{array}{ll}\text { DH } & \text { District Heating } \\ \text { DHW } & \text { Domestic Hot Water } \\ \text { GIS } & \text { Geographic Information Systems } \\ \text { ILP } & \text { Integer Linear Programming } \\ \text { MILP } & \text { Mixed-Integer Linear Programming } \\ \text { MST } & \text { Minimum Spanning Tree } \\ \text { Res } & \text { Resource } \\ \text { SH } & \text { Space Heating } \\ \text { SP } & \text { Shortest Path }\end{array}$

b Building

c Cluster

$C_{i n v} \quad$ Annualized investment cost

$C_{o p} \quad$ Yearly operating cost

$C_{t o t} \quad$ Total annual cost

$\mathrm{d}$

E Edge set of the graph

G Graph

$1_{r} \quad$ Road segment length

$\mathrm{L}_{\mathrm{DH}} \quad$ Total length of the DH network

$\mathrm{m}_{\text {res }} \quad$ Resource mass flow

$\mathrm{N}_{\mathrm{b}} \quad$ Number of buildings

$\mathrm{N}_{\mathrm{s}} \quad$ Number of subclusters

$\mathrm{p} \quad$ Heating power demand

$\dot{\mathrm{q}} \quad$ Thermal power

u Unit

r Road segment

$\mathrm{T} \quad$ Edge set of the minimum spanning tree

$\mu \quad$ Center of the subclusters

$v_{\min } \quad$ Lower heating demand bound

$v_{\max } \quad$ Upper heating demand bound

\section{References}

[1] IEA, Technology Roadmap - Geothermal Heat and Power, 2011.

[2] U.S. Energy Information Administration, Annual Energy Review $2008_{\text {p08 }}^{1080}$ Report DOE/EIA-0384(2008), U.S. Department of Energy (DOE), $2009_{1082}$

[3] Werner S., ECOHEATCOOL The European heat market, 2006, Available from: http: / / www . euroheat.org/ecoheatcool

[4] Fox B., Sutter D. and Tester W., The thermal spectrum of low-temperature energy use in the United States, Energy Environ. Sci. 4, 2011, 3731-3740 ${ }_{\text {T086 }}$

[5] Constantinos A., Kalliopi D. and Dascalaki E., Heating energy consump $p_{\overline{1087}}$ tion and resuling environmental impact of European apartment buildings $s_{1088}$ Energy and Buildings, 2005, 37, 429-442.

[6] Connolly D. et al., Heat Roadmap Europe: Combining district heating ${ }_{090}$ with heat savings to decarbonise the EU energy system., Energy Polic $\}_{091}$ $65,2014,475-489$.

[7] Finney N. et al., Modelling and mapping sustainable heating for cities. ${ }_{\text {.po93 }}^{1092}$ Applied Thermal Engineering 53, 2013, 246-255.

[8] Nielsen S., Möller B., GIS based analysis of future district heating poten $_{\overline{1095}}^{1094}$ tial in Denmark., Energy 57, 2013, 458-468.
[9] Möller B., Lund H., Conversion of individual natural gas to district heating: Geographical studies of supply costs and consequences for the Danish energy system., Applied Energy 87, 2010, 1846-1857.

[10] Lam H., Klemes J., Kravanja Z., Model-size reduction techniques for large-scale biomass production and supply networks., Energy 36, 2011, 4599-4608.

[11] Girardin L., Maréchal F., Dubuis M., Calame-Darbellay N., Favrat D., EnerGis: A geographical information based system for the evaluation of integrated energy conversion systems in urban areas, Energy 35, 2010, 830-840.

[12] Girardin L., Ph.D. thesis, Ecole Polytechnique Fédérale de Lausanne, 2012.

[13] Werner S., District heating for one-family houses - heat losses and distribution costs, The Swedish district heating association, report FVF 1997:1, Stockholm, 1997.

[14] IPCC, Special Report on Renewable Energy Sources and Climate Change Mitigation, Cambridge University Press, United Kingdom and new York, NY, USA, 2011

[15] Persson U. and Werner S., Heat distribution and the future competitiveness of district heating, Applied Energy 88, 2011, 568-576.

[16] Reidhav C. and Werner S., Profitability of sparse district heating, Applied Energy 85, 2008, 867-877.

[17] Falke T., Krengel S., Meinerzhagen A., Schnettler A., Multi-objective optimization and simulation model for the design of distributed energy systems, Applied Energy 184, 2016, 1508-1516.

[18] Lee D. and Lin A., Generalized delaunay triangulation for planar graphs, Discrete \& Computational Geometry 1, 1986, 201-217.

[19] Delaunay B., Sur la sphère vide, Bulletin de l'académie des sciences de l'URSS, 1934.

[20] Kruskal Joseph B., On the Shortest Spanning Subtree of a Graph and the Traveling Salesman Problem, Proceedings of the American Mathematical Society 7, 1956, 48-50.

[21] Johnson Donald B., Efficient algorithms for shortest paths in sparse networks, Journal of the ACM 24, 1977, 1-13.

[22] Berge C., The theory of graphs, Dover publications, INC., 2001.

[23] Gebremedhin A., Introducing District Heating in a Norwegian town Potential for reduced Local and Global Emissions, Applied Energy 95, 2012, 300-304.

[24] Hepbasli A. and Canakci C., Geothermal district heating applications in Turkey: a case study of Izmir-Balcova, Energy Conversion and Management 44, 2003, 1285-1301

[25] Moret S., Gerber L., Amblard F., Peduzzi E. and Maréchal F., Geothermal Energy and Biomass Integration in Urban Systems: a Case Study, Stanford University, Stanford, CA (USA), 2015.

[26] Courchesne Tardif A., Conception et optimisation de systèmes énergétiques hybrides pour communautés durables, 2011.

[27] Tacher L., An attempt of deep geological stratigraphical model in the area of Lausanne city, 2014.

[28] EHP, Euroheat and Power-District Heating and Cooling-2007 Statistics, 2007.

[29] GRUNEKO SCHWEIZ AG, 20 Années de géothermie à Riehen: rétrospectives, expériences du projet et possibilités d'optimisation, 2014.

[30] POYRY, The potential and costs of district heating networks, 2009.

[31] Amblard, F, Geothermal energy integration in urban systems - The case study of the City of Lausanne, 2015.

[32] Fazlollahi S., Doctoral Thesis, EPFL, Lausanne, 2014.

[33] McQueen J.B., Some Methods for classification and Analysis of Multivariate Observations, Proceedings of 5th Berkeley Symposium on Mathematical Statistics and Probability, University of California Press, pp. 281-297, 1965

[34] FOTDanmark. Common public geodata. fot danmark. dk. 2012.

[35] Greater London Authority, London heat map http://www. londonheatmap.org.uk/(visited on 14/04/2016).

[36] IFAF, HeatMap - Visualisierung von Heizenergieverschwendungen in öffentlichen Gebäuden durch eine Heatmap http://www. ifaf-berlin.de/projekt-details/datum////heatmap/ (visited on 14/04/2016).

[37] Centre de Recherches énergétiques et Municipales CREM http:// WwW. crem. ch/ (visited on 18/04/2016).

[38] Beckers F., Lukawski Z., Reber J., Anderson J., Moore C. and Tester W., Introducing GEOPHIRES V1.0: Software package for estimating lev- 
elized cost of electricity and/or heat from enhanced geothermal systems, Stanford University, Stanford, CA (USA), 2013.

[39] Harrison R., Mortimer N. D., Smarason O. B., Geothermal heating: a handbook of engineering economics, 1990.

[40] Einarsson S. S., Geothermal District Heating,Geothermal Energy, UNESCO Paris, 1973, 123-134.

[41] EUROPEAN COMMISSION, Energy Roadmap 2050,2011.

[42] Moret S., Peduzzi E., Gerber L., Maréchal F. Integration of deep geothermal energy and woody biomass conversion pathways in urban systems. Submitted to Energy Conversion and Management. 2016.

[43] QGIS Development Team. QGIS Geographic Information System. Open Source Geospatial Foundation. 2009. http://qgis. osgeo.org

[44] Office fédéral de la statistique. Registre fédéral des bâtiments et des logements. https://www.housing-stat.ch/index_fr.html (visited on 02/08/2016).

[45] CADOUEST. http://www. cadouest.ch/(visited on 02/08/2016). 